\title{
OS EMPRESÁRIOS, A POLÍTICA E A WEB: mapeando as atividades políticas nos portais das federações de indústrias brasileiras
}

\author{
Sérgio Braga* \\ Maria Alejandra Nicolás**
}

\begin{abstract}
Resumo: O objetivo do trabalho é apresentar os resultados de nossa pesquisa sobre o "grau de informatização" dos portais das federações das indústrias de 27 unidades subnacionais brasileiras, especialmente o mapeamento que efetuamos das atividades políticas desenvolvidas pelos empresários a partir desses portais. Esse objetivo geral desdobra-se em dois objetivos específicos: a) apresentar uma proposta de mensuração do grau de informatização e de utilização da Internet pelas federações de indústrias, visando a avaliar o quanto estas entidades avançaram no uso da Web para divulgar suas atividades e interagir com o cidadão comum; b) elaborar e aplicar instrumentos teórico-metodológicos para a análise de tais dados, especialmente para a avaliação da eficácia da Internet como instrumento de organização da ação política do empresariado.
\end{abstract}

Palavras-chave: Internet e Política; ação política empresarial; federações de indústrias.

\footnotetext{
" Doutor em Desenvolvimento Econômico pela Universidade Estadual de Campinas (Unicamp), é professor na Universidade Federal do Paraná (UFPR) e coordenador do convênio estabelecido entre a Federação das Indústrias do Paraná (FIEP) e a UFPR para a implantação do Sistema de Monitoramento dos Eleitos, no âmbito da Rede de Participação Política do Empresariado.E-mail: ssbraga@uol.com.br

** Mestre em Sociologia pela Universidade Federal do Paraná (UFPR) e especialista em Gestão de Programas, Projetos e Políticas Sociais pela Pontífice Universidade Católica do Paraná (PUC-PR), coordena o grupo de pesquisadores do projeto "Quem são e o que fazem os políticos paranaenses? Avaliando e monitorando a atuação das elites políticas paranaenses pela internet (2007-2011)"; desenvolvido em convênio com a Federação das Indústrias do Paraná (FIEP).

Versões preliminares deste texto foram apresentadas no VI Workshop Empresários, Empresas e Sociedade, realizado em março de 2008 na Universidade Federal Fluminense (UFF), em Niterói/RJ, e no IV Congresso da Associação Latinoamericana de Ciência Política (Alacip), realizado em San José/Costa Rica, em agosto de 2008.
}

Recebido em 2 jun. 2008 e aprovado em $1^{\circ}$ set. 2008. 


\section{Introdução}

A questão do impacto das novas Tecnologias de Informação e Comunicação (TICs) na arena política e na esfera pública tem sido objeto de uma bibliografia crescente (Gomes, 2007). Entretanto, via de regra esses estudos examinam órgãos da administração pública e atores políticos tradicionais, tais como websites de instituições legislativas e governamentais, não se detendo no estudo sistemático dos atores da "sociedade civil" como, por exemplo, movimentos sociais, sindicatos, entidades empresariais e outras associações do gênero. Por sua vez, embora já exista um corpo razoável de estudos sobre a atuação política do empresariado no novo ciclo democrático brasileiro iniciado com a promulgação da Constituição de 1988 (Boschi et. al., 2000; Diniz, Boschi, 2004; Mancuso, 2004, 2007; Schneider, 2004, p. 93-127), esses estudos enfatizam mais a presença do empresariado em instâncias tradicionais de atuação política, tais como órgãos parlamentares e legislativos, grupos de pressão, conselhos e câmaras setoriais, e órgãos de representação de interesses no interior no aparelho de Estado. Ainda são escassas pesquisas que busquem analisar de maneira mais sistemática as relações políticas estabelecidas pelo empresariado com outros atores da sociedade civil no novo ciclo democrático brasileiro e são quase inexistentes trabalhos que examinem como os empresários estão usando as TICs em geral, e a internet em particular, para organizar sua ação política e associativa, assim como para divulgar e desenvolver novas formas de atuação política e de promoção da cidadania.

Nesse sentido, uma importante contribuição da literatura mais recente foi demonstrar que o empresariado brasileiro, especialmente o empresariado industrial, engajou-se num crescente processo de organização e mobilização ao longo da década de 1990, transcendendo os limites dos arranjos corporativos tradicionais, e que tem nos órgãos legislativos um importante lócus político de atuação (Diniz, 2000, Mancuso, 2007). Assim, presente em 
várias frentes de atuação política e com intensa participação na arena legislativa como grupo de pressão, a influência política do empresariado vem se consolidando ao longo dos anos 90, tendo presença ativa em campanhas tais como o movimento contra o "Custo Brasil" (Mancuso, 2007), nas negociações sobre a ALCA e a inserção externa no Brasil ao longo da década de 1990 (Oliveira, 2003), e também nos debates sobre alternativas de desenvolvimento que permearam a agenda governamental brasileira a partir da crise do modelo neoliberal no final desta década (Diniz, 2004). Esses estudos mais recentes, portanto, contestam as teses tradicionais, bastante influentes até os anos 90, segundo os quais o empresariado brasileiro seria um ator político incapaz de ação coletiva, tanto no plano intra quanto intersetorial, em virtude de sua adesão ao sistema corporativista de interesses implantado no pós-1930 (Schneider, 2004: Power, Doctor, 2002).

Assim, dentro do contexto de novos campos de investigação abertos pelas recentes abordagens sobre as relações entre empresariado e sistema político (Mancuso, 2007), é indispensável que sejam realizadas pesquisas sobre estas novas arenas de atuação política do empresariado e de sua interação com outros atores. O objetivo deste artigo é empreender uma reflexão nesse sentido e contribuir para o avanço do conhecimento das novas formas de ação coletiva empresarial que se abrem a partir da crise do sistema corporativo que vigorou até a década de 1990 e do surgimento de um sistema mais complexo e diversificado de representação de interesses do empresariado. Procuraremos cumprir este objetivo abordando uma temática, a nosso ver, ainda insuficientemente analisada, tanto no plano da literatura brasileira como no da internacional, qual seja, como os empresários estão utilizando os recursos da internet e das TICs para promover formas inovadoras e mais participativas de ação política. Sublinhe-se que nosso objetivo fundamental, no estágio atual de pesquisa e reflexão, é traçar um panorama abrangente de como os empresários usam a Web para promover atividades políticas vis- 
$\grave{a}$-vis outras atividades que podem ser veiculadas nos portais de suas associações, tradicionalmente consideradas como típicas do grupo empresarial; por conseguinte, não será possível, aqui, empreender análises em profundidade de todos os fenômenos observados. Dentro desse contexto, procuraremos apresentar os resultados de nossa pesquisa sobre o "grau de informatização" dos portais das federações de indústrias de 27 unidades subnacionais brasileiras, especialmente o mapeamento que efetuamos das atividades políticas desenvolvidas pelo empresariado industrial a partir desses portais. ${ }^{1}$ Esse objetivo geral desdobra-se em dois objetivos específicos:

a) apresentar uma proposta de análise e mensuração do grau de informatização e de utilização da internet pelas federações de indústrias, visando avaliar o quanto estas entidades avançaram no uso da Web para divulgar suas atividades e interagir com o cidadão comum;

b) elaborar e aplicar instrumentos teórico-metodológicos para a análise de tais dados, especialmente para a avaliação da eficácia da internet como instrumento de organização da ação política do empresariado. ${ }^{2}$

Procuramos cumprir esses objetivos por meio da elaboração e análise de uma planilha especifica, onde sistematizamos informações referentes a cerca de 120 variáveis básicas passíveis de serem localizadas nos sítios das federações de indústrias examinadas. A partir da aplicação da planilha, avaliamos as informações contidas em cada item e procuramos efetuar um mapeamento abrangente sobre como essas associações industriais avançaram no uso das TICs, especialmente para organizar e divulgar suas atividades políticas.

Assim sendo, para análise e acompanhamento do "grau de informatização" dos sítios de tais organizações, pretendemos sugerir uma metodologia que cumpra os seguintes requisitos: 1) seja de fácil aplicação e entendimento, permitindo a qualquer pesquisador ou 
cidadão com acesso à internet utilizar estes recursos para monitorar a natureza do uso da internet pelos vários organismos empresariais examinados; 2) apresente, de forma condensada, o maior número possível de informações, possibilitando ao pesquisador e ao cidadãointernauta uma visão abrangente douso de tais recursos, e aumentandolhes a percepção acerca das potencialidades e vicissitudes do uso das TICs para a organização de sua ação coletiva e para a criação de novas formas de participação democrática. Portanto, o intuito mais geral do presente artigo é o de fornecer evidências que permitam uma avaliação mais precisa e empiricamente fundamentada do nível de transparência das federações industriais examinadas, tal como mensurado pela utilização que tais entidades fazem da Web para divulgar suas atividades, bem como pela verificação das formas de ação política e associativa que estão difundindo a partir dos seus portais.

Nesse sentido, o objetivo mais geral subjacente à presente investigação é verificar se a internet e os websites das federações estão apenas reproduzindo a "política como usual", como é defendido por uma determinada vertente de analistas (Margolis, Resnik, 2000), ou se está agregando novas dimensões à atividade política dos grupos sociais observados, ao integrá-los num "sistema político virtual" que pode lançar a ação política das entidades empresariais e civis, de uma maneira geral, para novos patamares, tornando-as mais transparentes, participativas e fortalecendo os laços que as vinculam aos segmentos representados por tais grupos (Norris, 2001). ${ }^{3} \mathrm{O}$ enfoque adotado no presente texto se vincula mais a esta última vertente, na medida em que nossa proposição básica é a de que a internet pode repercutir significativamente na organização de tais atores, tornando mais eficazes e transparentes suas atividades e dando ensejo a novas formas de ação coletiva e participação política, contribuindo para integrar melhor o empresariado em ações de estímulo à cidadania mais próximas de sua coletividade de origem, e 
tornando mais transparentes suas formas de atuação em arenas mais convencionais de representação de interesses.

Para abordar estas questões, organizaremos nossa exposição da seguinte forma: a) inicialmente, esclareceremos alguns aspectos da metodologia de análise por nós empregada para estudar os portais das federações de indústrias, a qual consiste numa versão modificada de técnicas de análises que já utilizamos em estudos anteriores sobre órgãos legislativos (Braga, 2007); b) em segundo lugar, discutiremos os resultados da aplicação de tal metodologia, efetuando um mapeamento descritivo e uma análise quantitativa das informações disponíveis nos websites de tais entidades; c) por fim, a partir da análise dos casos dos websites de algumas associações industriais mais organizadas e da Rede de Participação Política do Empresariado, procuraremos analisar aspectos mais substantivos do tema pesquisado e tecer algumas considerações sobre os potenciais do uso das TICs para uma atuação mais transparente e eficaz do empresariado na esfera pública.

Isto posto, passamos a expor os elementos fundamentais da metodologia de análise e coleta de dados usada em nossa pesquisa.

\section{Metodologia de análise}

Nossa metodologia se estruturou no sentido de desenvolver instrumentos que possibilitem uma análise comparativa da ação associativa e política das diferentes federações de indústrias a partir de seus sítios na internet, assim como de mensurar o "grau de informatização" (ou transparência) desses sítios. A preocupação se corporifica na composição de um indicador que possibilite a apreensão sintética da maior ou menor amplitude de frequência das variáveis que são objeto de exame no texto. Como registrado, procuramos cumprir a tarefa através da elaboração e preenchimento de uma planilha específica com cerca de 120 itens empregados para 
a coleta e sistematização de informações sobre diversos aspectos ou variáveis passíveis de ser localizados em sítios das federações de empresários (Anexo 1).

Sublinhe-se que o emprego dessa metodologia compatibilizase com algumas das motivações básicas desta pesquisa. Assim, por um lado temos uma preocupação de ordem descritiva, na medida em que buscamos detectar a frequência de itens de atividade política vis-à-vis outros tipos de atividades presentes nos sítios das associações examinadas, e também uma preocupação de ordem analítica, na medida em que procuraremos testar algumas hipóteses, expectativas e proposições teóricas a partir do exame e discussão de tais evidências, preocupação esta que, a nosso ver, justifica-se para nos demarcarmos do tom excessivamente impressionista de algumas análises que investigam o impacto das TICs no sistema político.

Inicialmente listamos, com base na bibliografia pesquisada e na consulta aos mapas dos sítios de diferentes entidades, uma série de elementos presentes em websites e que consideramos relevantes para uma visualização abrangente do funcionamento desses órgãos, bem como para a composição de nosso indicador. É importante sublinhar que todas as variáveis incluídas na planilha foram extraídas da literatura ou encontradas nos sítios das associações analisadas. Assim, a pontuação máxima corresponde a um sítio hipotético que contém todos os itens enumerados.

Elaboramos uma planilha para verificar se os itens estão presentes em cada sítio das federações de indústrias (incluindo a CNI) e, em seguida, a preenchemos, classificando-os de acordo com uma escala não contínua que vai de 0 a 30 , pontuando os itens de acordo com sua presença nos sítios e ponderando-os segundo o grau de relevância para o aumento da interação de tais entidades com a opinião pública e para o aumento de seu grau de transparência. Deve-se sublinhar ainda que, além de constatar a presença de cada item nos sítios, testamos a funcionalidade de cada uma das variáveis 
analisadas. Por isso, atribuímos peso desigual na pontuação de cada variável, em virtude de sua funcionalidade e de sua maior ou menor importância para o acesso do pesquisador e do cidadão-internauta às informações sobre as diferentes entidades examinadas.

Além disso, seguindo diretrizes por nós esboçadas em estudos anteriores (Braga, 2007), procuramos subdividir nossa metodologia em dois momentos básicos: 1) definição das dimensões mais relevantes a serem analisadas nos websites das associações industriais; 2) definição de um critério de pontuação e de ponderação das diferentes variáveis examinadas. Essa dupla preocupação metodológica justifica-se tendo em vista o objetivo mais geral do presente estudo que é o de empreender uma avaliação abrangente e "empiricamente orientada" dos principais recursos existentes nos websites das associações industriais, cotejando-os com os recursos disponíveis para a promoção de atividades políticas. Sendo assim, é uma preocupação fundamental deste artigo a de desenvolver instrumentos analíticos precisos para propiciar essa comparação, mesmo com o risco de atribuir um caráter descritivo às considerações feitas a seguir.

A análise dos sítios foi estruturada a partir do grau de recursos disponibilizados pelas associações empresariais na Web, considerando as seguintes dimensões básicas:

1) Informações gerais/navegabilidade - recursos existentes nas home pages das federações e que facilitam e estimulam a navegação do internauta num primeiro contato com esses sítios (variáveis 1 a 11 da planilha).

2) Informações institucionais e sobre as elites dirigentes funcionamento das entidades pesquisadas, organograma e composição, desde os objetivos e missão da entidade até dados sobre diretoria e atas de reunião dos conselhos. Essa dimensão abrange também informações sobre o 
recrutamento dos atores que participam das instâncias dirigentes e demais órgãos deliberativos das associações, bem como sobre suas rotinas administrativas (variáveis 12 a 26).

3) Serviçosbásicoseoportunidades denegócios/investimentos - informações sobre serviços e oportunidades ofertados aos associados, tais como assessoria jurídica e trabalhista, e estudos sobre a conjuntura econômica, dentre outras informações sobre o comportamento dos negócios (variáveis 27 a 38).

4) Educação e cidadania: programas voltados para atividades educacionais e de promoção da cidadania de uma maneira geral, mas sem cunho estritamente político (variáveis 39 a $50)$.

5) Comunicação e informação: serviços de mídia e informação disponibilizados pela entidade, tais como: serviço de notícias, clipping, arquivos sonoros e de vídeo, e mesmo transmissão de rádio e TV on-line (variáveis 50 a 62).

6) Economia e tecnologia: informações básicas sobre assuntos de natureza econômica e tecnológica disponibilizadas aos associados, tais como estudos e dados sobre nível de emprego, e desempenho da indústria e assim por diante (variáveis 63 a 80).

7) Atividades políticas e cívicas - tais como: ação dos empresários industriais em órgãos legislativos, posicionamento no tocante a alguns temas básicos em debate na arena política e outras atividades de caráter cívico que demandam uma maior interação com a sociedade civil (variáveis 81 a 102). 
8) Links para outras instituições - fato indicativo de "integração em rede" das federações de indústrias com outras associações e entidades, ou a maneira pela qual elas interagem com outros atores políticos por intermédio da web (variáveis 103 a 120).

Grosso modo, tais dimensões traduzem detalhamentos e correspondem às funções básicas (acessibilidade ao público, recrutamento e organização da ação social, comunicação, informação, interatividade e conexão em rede com outros atores, participação no processo decisório coletivo) que podem ser desempenhadas pelas TICs para auxiliar a organização e atuação político-social e comunitária das associações examinadas e que estruturam sua ação na esfera pública.

No que se refere à segunda dimensão de nossa metodologia de análise dos sítios, outra questão a ser enfrentada foi a dos critérios para a pontuação dos itens, bem como a de uma análise, mesmo exploratória, que articulasse aspectos qualitativos e quantitativos presentes nos sítios. Dentre outras razões, a precaução era necessária porque, embora os links para as informações constassem dos sítios pesquisados, muitas vezes não se encontram acessíveis ao cidadãointernauta ou o seu acesso é precário. Também vale destacar que nem todas as variáveis têm o mesmo peso na organização dos sítios, pelo que é necessário definir um fator de ponderação para a pontuação dos itens. Procuramos resolver tais problemas pontuando as variáveis analisadas de acordo com os critérios mostrados no Quadro 1.

O critério para definir o grau de importância das variáveis examinadas foi o de sua relevância para o aumento da transparência da atuação de tais entidades na esfera pública, tendo em vista a disponibilidade média dos recursos tecnológicos difundidos e empregados pelos gestores de tais websites. Isto posto, partimos para a operacionalização de nossa metodologia, ou seja, para a 
análise do grau de transparência ou de informatização das federações industriais segundo os critérios acima expostos. A pontuação dos sítios foi obtida aplicando o quadro acima à planilha que elaboramos para avaliá-los.

\section{Quadro 1 - Critérios de pontuação dos sites}

\begin{tabular}{|l|c|c|c|}
\hline $\begin{array}{c}\text { Tipo de } \\
\text { informação }\end{array}$ & $\begin{array}{c}\text { Anfiação } \\
\text { completas } \\
\text { e/ou } \\
\text { satisfatórias } \\
\text { (c) }\end{array}$ & $\begin{array}{c}\text { Informações } \\
\text { incompletas } \\
\text { e/ou } \\
\text { nsatisfatórias } \\
\text { (i) }\end{array}$ & $\begin{array}{c}\text { Sem } \\
\text { informação }\end{array}$ \\
\hline Importante e essencial & 15 a 30 & 5 a 15 & 0 \\
\hline $\begin{array}{l}\text { Importante, mas não } \\
\text { tão essencial }\end{array}$ & 10 a 15 & 3 a 5 & 0 \\
\hline Menos importante & 5 & 3 & 0 \\
\hline
\end{tabular}

A visita aos sítios foi empreendida intermitentemente entre os meses de janeiro e fevereiro de 2008, sendo realizada uma nova rodada de visitas na primeira semana de março para checar e atualizar a funcionalidade de cada variável analisada. As informações contidas neste artigo, portanto, foram atualizadas até esta última data, embora incluam certa margem de erro devido ao grande número de "experimentos" necessários para a comprovação da funcionalidade das variáveis observadas, bem como à natureza "dinâmica" da organização das home page. ${ }^{4}$

Deve-se esclarecer, por fim, que pesquisamos apenas os websites das federações de indústrias e os sistemas ou portais a elas associados (tais como Sesi, Senai e IEL, onde eram disponibilizadas informações sobre algumas das variáveis pesquisadas), excluindo de nosso estudo outras entidades tais como os Centros Industriais que, embora estreitamente associados aos sistemas FIES, são entidades de natureza distinta, e não um mero prolongamento destas últimas. 


\section{Análise dos dados}

As federações de indústrias analisadas estão enumeradas no Quadro 2, acompanhadas das siglas e respectivos endereços eletrônicos. Para simplificar, na representação gráfica serão utilizadas as siglas dos Estados a que pertencem. Ao todo foram analisados vinte e oito websites, distribuídos pelas cinco regiões brasileiras.

\subsection{Informações gerais/navegabilidade}

A primeira dimensão da análise refere-se a "Informações gerais/navegabilidade" disponíveis ao público na "porta de entrada" dos sítios, onde ocorre um primeiro contato do internauta com as federações de indústrias que estão na $W e b$. Neste tópico, avaliamos a ocorrência dos itens mostrados na Tabela 1 , devido à sua importância para a orientação inicial do cidadão que navega pela internet, bem como para tornar a navegação nas home pages mais estimulante, sem informações de difícil apreensão. Um maior grau de presença de tais itens nos portais revela que seus gestores preocupam-se em atingir um público mais amplo, não necessariamente especializado, e diferente do público tradicional das federações.

Com efeito, pelo Gráfico 1, podemos observar que, dos 28 websites examinados, 12 atingiram níveis satisfatórios e acima da média na disponibilização de itens que facilitem a navegabilidade do cidadão-internauta, propiciando recursos básicos para uma navegação mais ativa além da mera recepção passiva de mensagens. ${ }^{5}$

A Federação das Indústrias do Estado de Pernambuco e a do Rio Grande do Norte atingiram a maior pontuação neste tópico. Outros sítios bem organizados, como, por exemplo, os da FIEP e da FIESP, não atingiram a mesma pontuação devido à ausência de enquête sobre temas de interesse da indústria, formulário para sugestão de melhoria, estatísticas de navegação e outros itens que, 


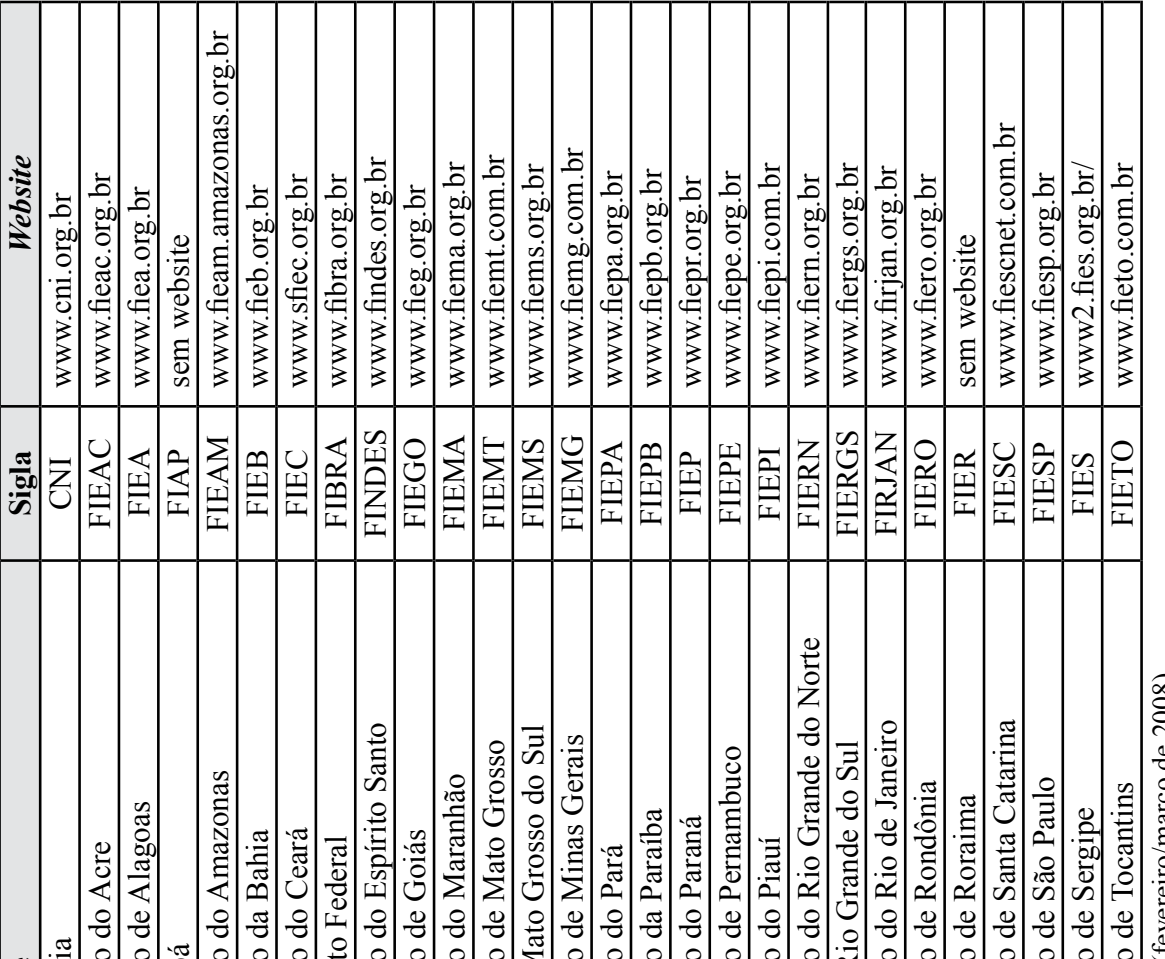

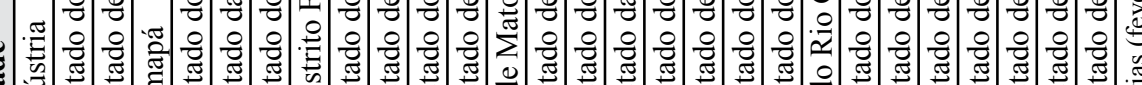

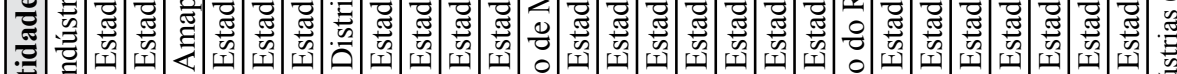

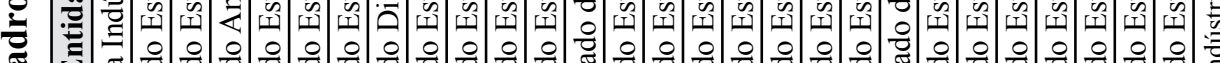
孚

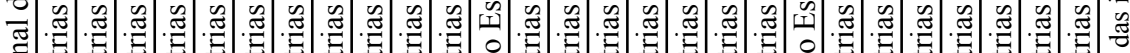

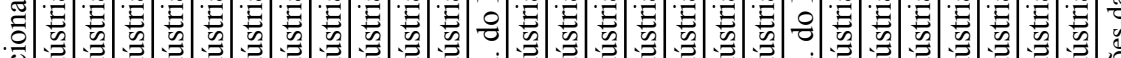

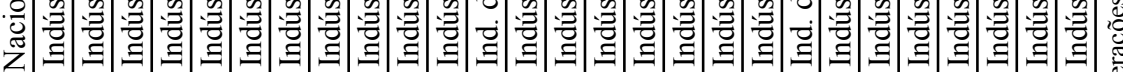

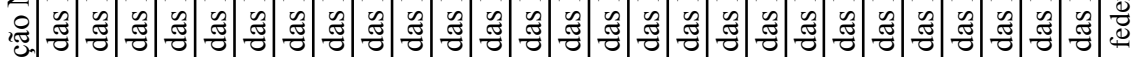
苟

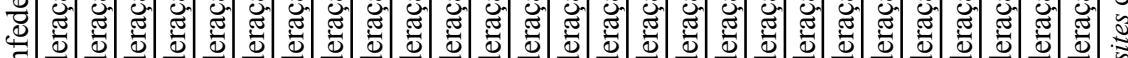

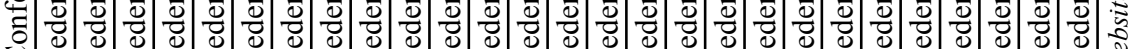

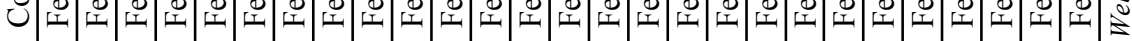

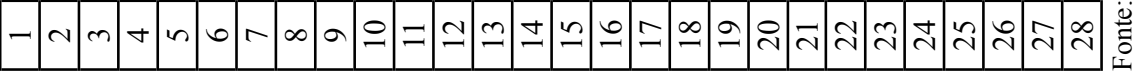




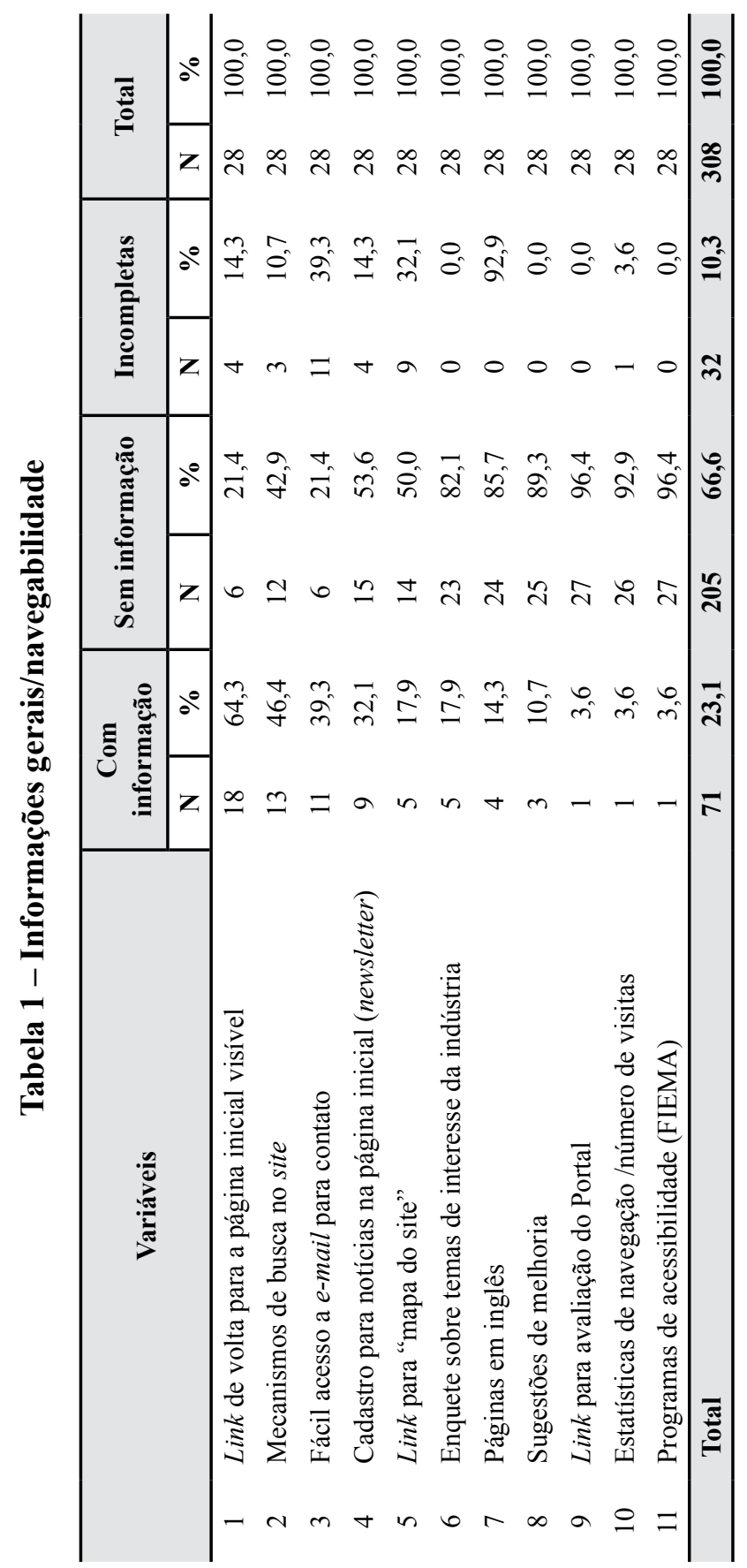


se inseridos na página inicial, poderiam tornar mais atrativa a navegação sem necessariamente sobrecarregar o sítios.

No tocante aos itens de maior freqüência, foram detectados: "link de volta para a página inicial sempre visível" em $64,3 \%$ dos portais; "mecanismos de busca no sítio" $(46,4 \%)^{6}$ e "fácil acesso a e-mail para contato" (39,3\%). Por sua vez, itens que possibilitariam uma maior interatividade do internauta com os portais, tais como "sugestões de melhoria" (10,7\%) e "link para avaliação do portal" $(3,6 \%)$, ainda são fracamente presentes, evidenciando um subaproveitamento dos portais no sentido de promover uma maior interação com o cidadão-internauta.

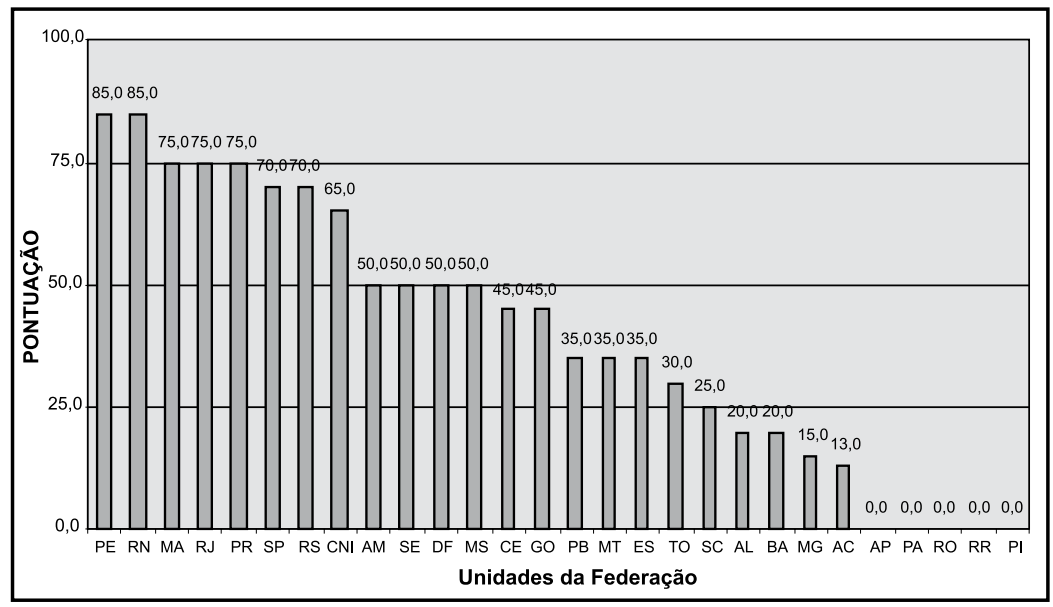

Gráfico 1 - Navegabilidade

Legenda para a pontuação:

75-100 - alto grau de informatização;

50-75 - médio a alto grau de informatização;

25-50 - médio a baixo grau de informatização;

0-25 - baixo grau de informatização. 


\subsection{Informações institucionais e sobre as elites dirigentes}

Uma importante dimensão do funcionamento das federações de indústrias é a disponibilização de dados detalhados sobre a biografia, a trajetória e o recrutamento dos dirigentes, assim como de detalhes mais aprofundados sobre o processo decisório e deliberativo de tais entidades, por exemplo, as pautas e atas das diretorias e conselhos deliberativos, e outros órgãos decisórios (Tabela 2). Essa dimensão da ação política dos diferentes atores através da web frequentemente tem sido obscurecida nos estudos sobre "internet e política", geralmente focados nas formas pelas quais a internet pode aumentar os mecanismos de "participação" política dos cidadãos (Gomes, 2005), dando importância secundária a outras dimensões também relevantes para o sociólogo político, tais como informações sobre o recrutamento e as ações estratégicas empreendidas pelas elites dirigentes. É evidente que, quanto mais informações sobre os dirigentes e quanto mais sistematicamente elas forem apresentadas, maior a possibilidade de acompanhar e controlar sua conduta, estreitando os vínculos de identificação simbólica, de representatividade e tornando mais transparente a ação desses segmentos das elites dirigentes para a opinião pública. Assim, a disponibilização de tais dados a um público mais amplo revela um elevado grau de preocupação do empresariado com a transparência de seu processo deliberativo, assim como com a publicização de aspectos relevantes de seus centros decisórios, contribuindo para aproximar o empresariado de outros atores sociais, tornando suas ações e deliberações mais transparentes.

Assim como no tocante à dimensão anteriormente examinada, há uma acentuada desigualdade no grau de disponibilidade de informação sobre os seus centros decisórios entre as várias federações de indústrias. Nesse sentido, das 28 entidades examinadas, apenas 12 


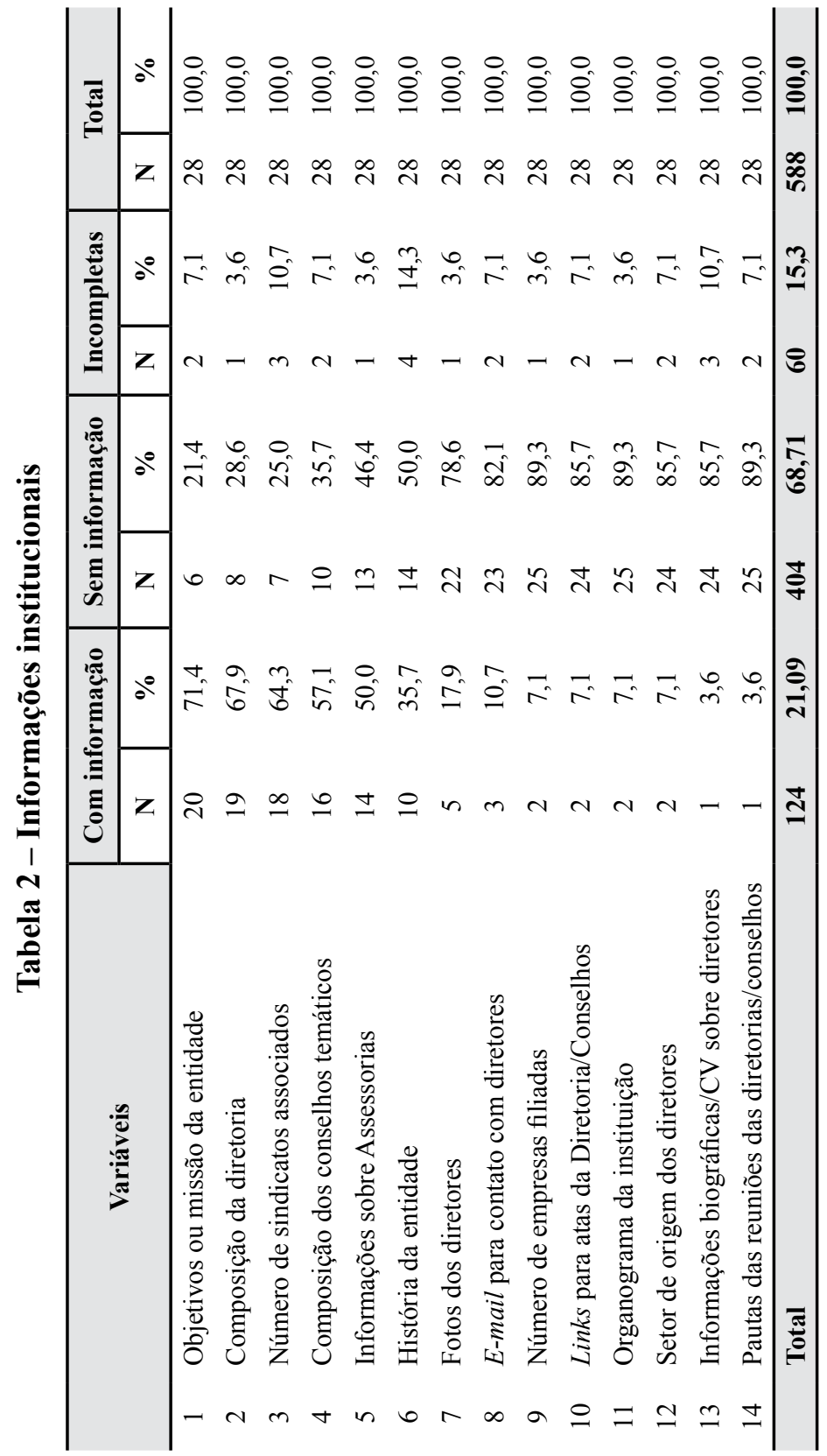


atingiram pontuação acima da média, revelando pouca preocupação em tornar transparentes informações sobre seus núcleos de decisão.

As informações constantes nos websites sobre os dirigentes e as instâncias deliberativas das entidades analisadas estão resumidas no Gráfico 2.

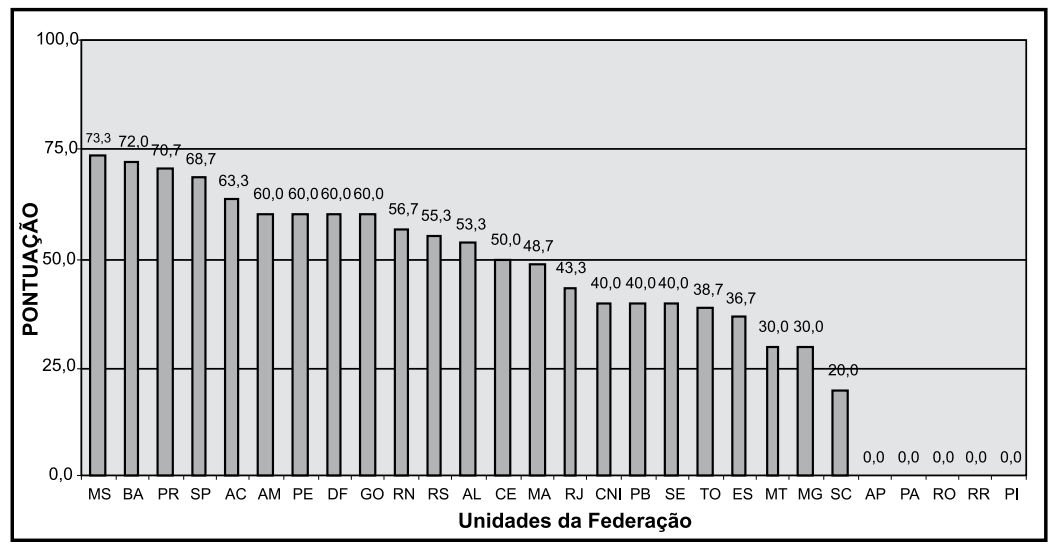

\section{Gráfico 2 - Informações institucionais/elites dirigentes}

Mais uma vez, a Federação das Indústrias do Paraná e a de São Paulo se destacam em relação às demais, embora sem atingirem a pontuação máxima e tendo sido superadas pelas de Mato Grosso e da Bahia. Um destaque a esse respeito é o portal da FIEMT, que disponibiliza informações curriculares e biográficas razoavelmente detalhadas sobre os membros de suas diretorias, assim como suas atividades empresariais e do ramo empresarial de que são originários, um procedimento pouco comum nas demais entidades representativas dos industriais.

Em relação à frequência dos itens, observamos a predominância daqueles que oferecem informações genéricas sobre a razão social das entidades, tais como "objetivo ou missão da entidade" 
(71,4\%), "composição da diretoria" (67,9\%), "número de sindicatos associados" (64,3\%). Por outro lado, alguns dos itens ou variáveis que poderiam tornar mais transparente o processo deliberativo das entidades, assim como o perfil de suas lideranças, ainda são fracamente presentes, revelando uma deficiente disposição de tais entidades em revelar o seu processo deliberativo ao escrutínio público, ao contrário do que ocorre nos órgãos legislativos federais. Por exemplo, as variáveis "links para atas de diretoria/conselhos da organização" (7,2\%), "informações curriculares e biográficas detalhadas sobre os diretores" (7,1\%), "pautas das reuniões de diretoria e conselhos" $(3,6 \%)$, apresentam baixíssimo percentual.

Em suma, ainda são bastante escassos os dados sobre o processo deliberativo das federações de indústrias, inversamente ao que ocorre com os órgãos legislativos brasileiros, especialmente em nível federal, que disponibilizam tais informações de forma mais transparente (Braga, 2007).

\subsection{Serviços básicos e oportunidades de negócios/ investimentos}

A Tabela 3 mostra as variáveis referentes ao desempenho dos websites das federações de indústrias quanto à presença de atividades políticas de serviços e informações que se destinam primordialmente ao seu público interno.

O Gráfico 3 fornece as médias de pontuação e, dentre todas as 'dimensões' examinadas, esta foi a que atingiu a maior frequência. Com efeito, a maior parte das federações conseguiu obter pontuação "muito alta" (12/28) e apenas 10 não atingiram pontuação satisfatória. Esse dado confirma nossa expectativa inicial, ou seja, a de que boa parte das informações contidas nos portais das federações de indústrias consistem de dados técnicos para atender interesses e demandas do seu público interno. 


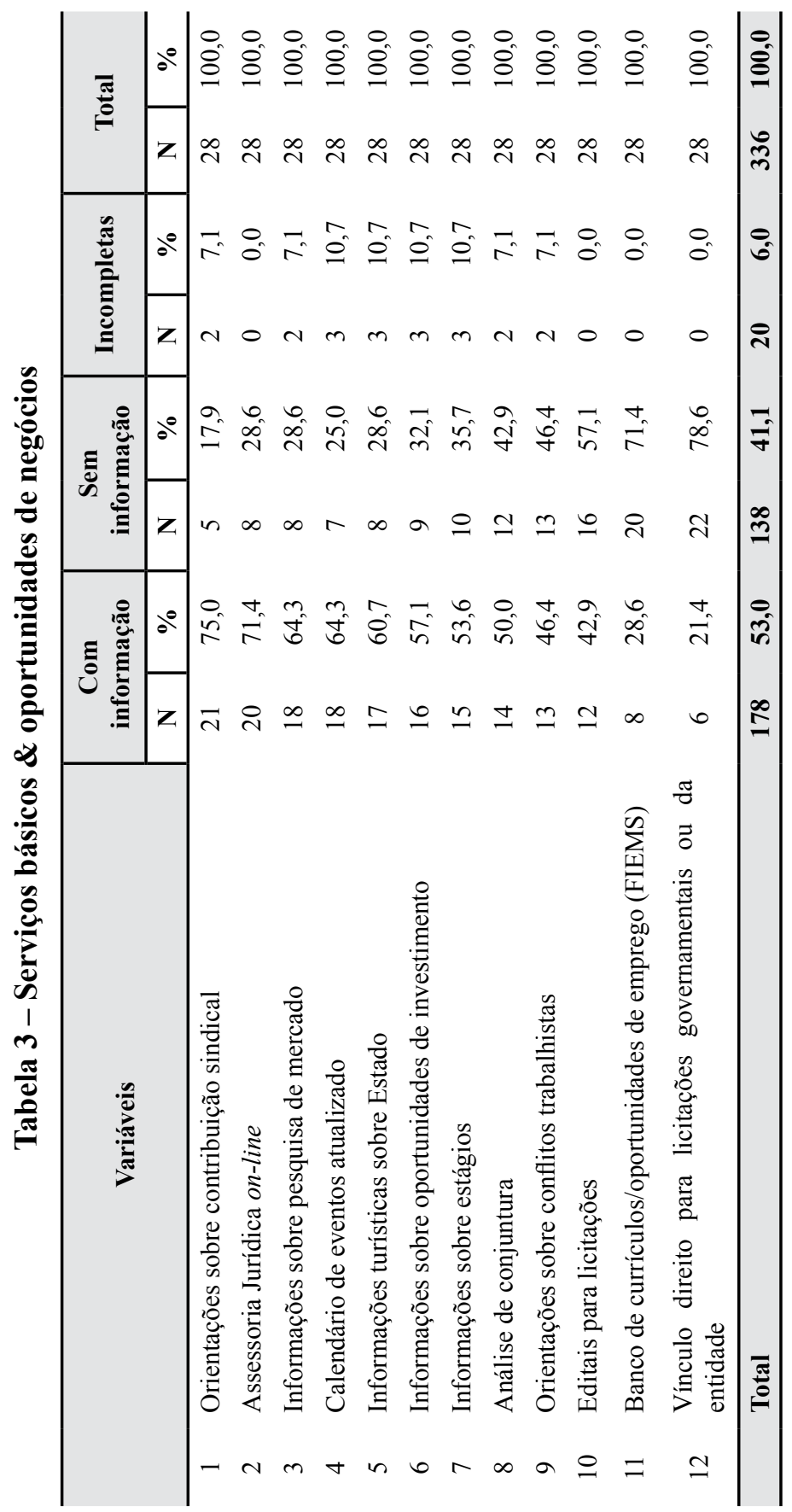




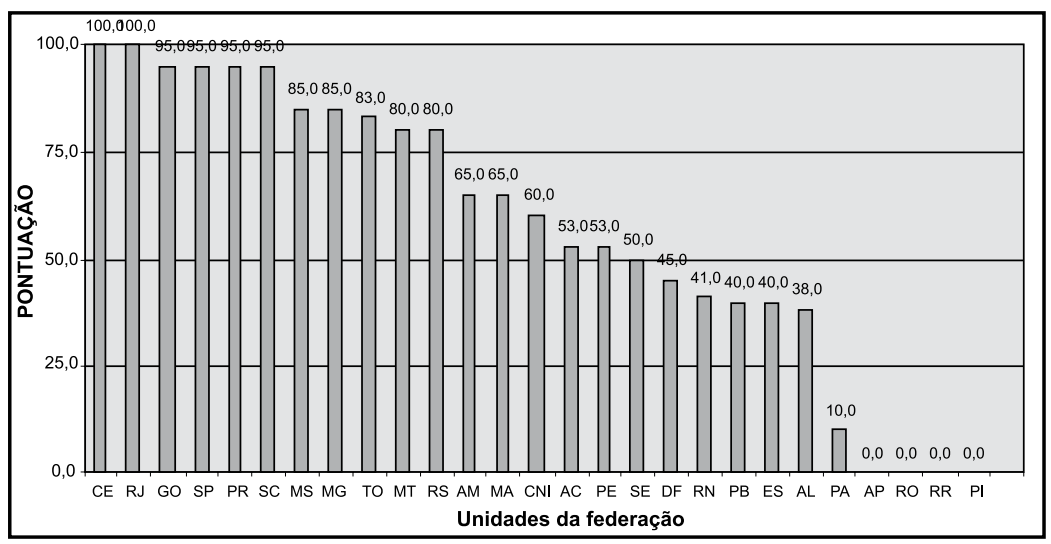

Gráfico 3 - Serviços básicos e oportunidades de investimentos

No tocante à frequência dos itens, podemos observar um elevado percentual para "orientações sobre contribuição sindical" (75,0\%), “informações sobre conflitos trabalhistas" (64,3\%) e "análise da conjuntura econômica" (60,7\%). Se considerarmos que, das 28 entidades examinadas, 5 estavam fora do ar ou apresentaram problemas de acesso durante a pesquisa, podemos inferir que a presença de alguns itens desta dimensão chega quase a cem por cento.

\subsection{Educação e cidadania}

Outro conjunto de variáveis importante que podemos observar nos portais das federações de indústrias são recursos destinados a divulgar e estimular programas educacionais e ações de cidadania que não envolvem necessariamente atividades de cunho cívicoassociativo ou político relacionadas com questões de natureza coletiva. Pelos dados coletados, podemos observar que a intensidade da presença de informações sobre tais atividades nos sítios está ligada à relevância que o sistema IEL/Sesi/Senai possui no funcionamento das federações de indústrias. 


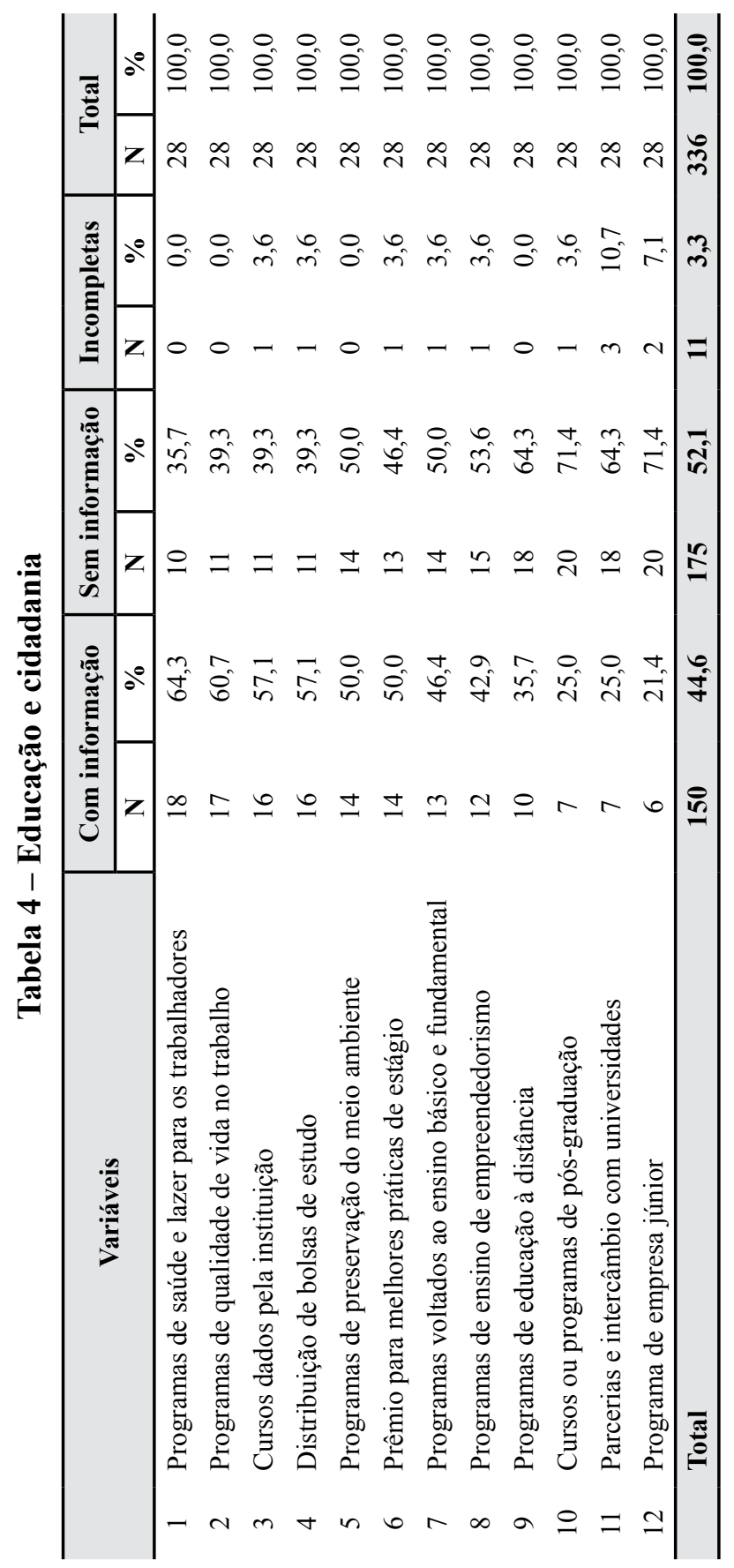




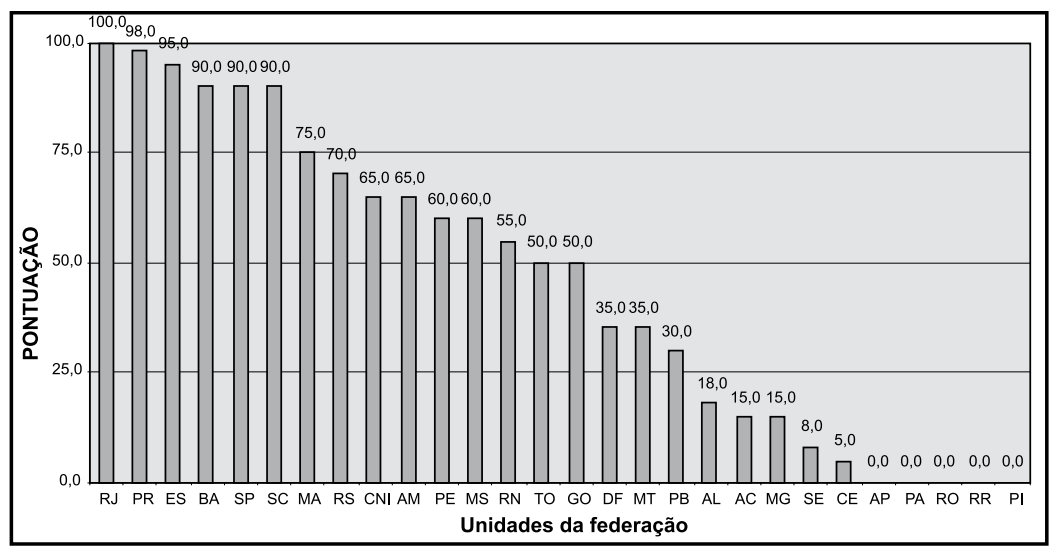

Gráfico 4 - Educação e cidadania

Pelo comportamento do Gráfico 4, podemos visualizar o elevado grau de presença de atividades educativas (especialmente ensino profissionalizante) e de ampliação dos direitos sociais patrocinadas pelas federações de indústrias, sendo que apenas 8 das que se encontravam on-line durante o período pesquisado não obtiveram pontuação satisfatória.

No tocante à frequência dos itens pesquisados, podemos destacar o baixo percentual de informações sobre "cursos e programas de pós-graduação" $(25,0 \%)$, e também de "parcerias e intercâmbios com instituições universitárias" (25,0\%), um tipo de atividade que ainda não possui grande visibilidade nos portais examinados, evidenciando um baixo grau de integração entre indústria e universidades, ou, ao menos, uma baixa propensão a tornar tais parcerias visíveis a partir dos websites das entidades.

Assim, pelos dados, podemos verificar que as entidades empresariais privilegiam aquelas atividades educativas de natureza mais instrumental, ou seja, voltadas para a formação e qualificação de mão de obra potencialmente empregável a curto prazo nas indústrias, em detrimento de atividades voltadas para pesquisas 
(mesmo que aplicadas) de longo prazo e de maior prazo de maturação. Portanto, ainda são poucas as evidências de promoção de atividades de pesquisa e desenvolvimento de maior prazo de maturação e de intercâmbio com instituições universitárias nos websites das associações empresariais, reproduzindo assim uma característica que também ocorre no mundo real, conforme observado por outros analistas (Schneider, 2004).

\subsection{Comunicação e informação}

Esta dimensão abrange os itens utilizados pelas diferentes associações empresariais para divulgar suas atividades junto à opinião pública, sem envolver necessariamente o estabelecimento de uma relação de interação ou o estímulo a feedback. Trata-se, basicamente, de recursos destinados a potencializar as funções de comunicação e informação estabelecidas pelas federações com a sociedade de uma maneira geral, utilizando recursos de mídia mais tradicionais (Tabela 5). A frequência dos diferentes itens de comunicação e mídia nos websites é indicada no Gráfico 5.

Também aqui é possível visualizar uma acentuada desigualdade na disponibilização de tais recursos nos portais, a amplitude variando dos que possuem transmissão de TV própria on-line (como a FIERGS) aos sem serviço de agências de notícia própria especializadas em temas industriais. Entretanto, de uma maneira geral, é forte a presença de itens de mídia nos websites das federações. Por exemplo, a grande maioria das entidades disponibiliza “informações produzidas por agência de notícias própria" (67,9\%), “informativo ou jornal semanal em formato pdf” (53,6\%), "anuário industrial do Estado em formato pdf" (53,6\%). Por outro lado, ainda é rara a disponibilização de recursos de mídia e de informação mais diversificados, tais como "livros e outras publicações em pdf" $(32,1 \%)$, "acesso a acervo das bibliotecas" $(25,0 \%)$, e "acervo de 


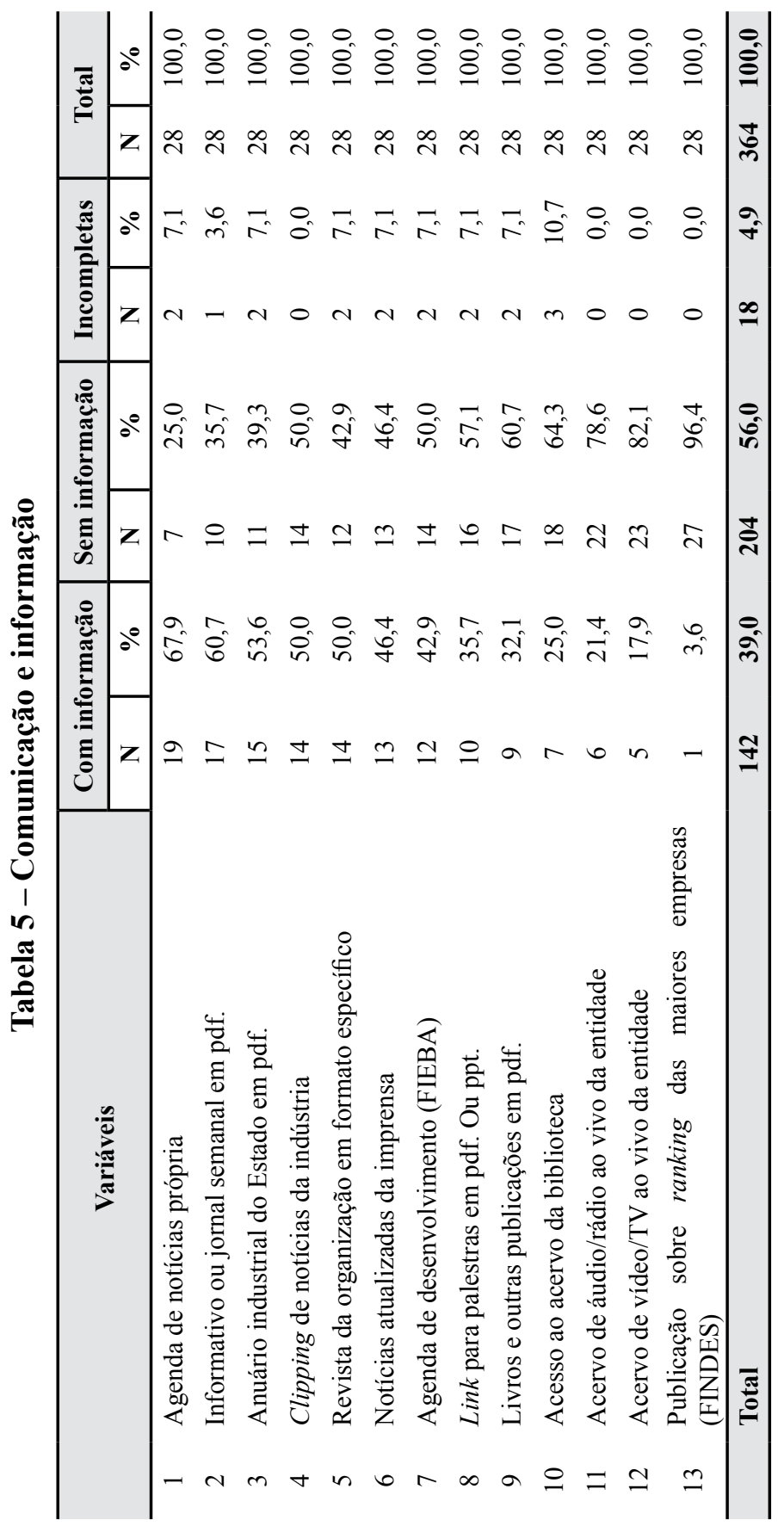


vídeo/TV ao vivo da entidade" (17,6\%). Entretanto, muitas das federações possuem link para a rádio da $\mathrm{CNI}$, que transmite on-line 24 horas a partir do sítio da entidade, revelando uma tendência à abdicação das entidades subnacionais na utilização destes recursos, e uma propensão a centralizar as responsabilidades na instituição de representatividade nacional (no caso, a CNI), o que indica uma ausência de preocupação em desenvolver ações mais integradas nas coletividades dentro das quais elas se inserem.

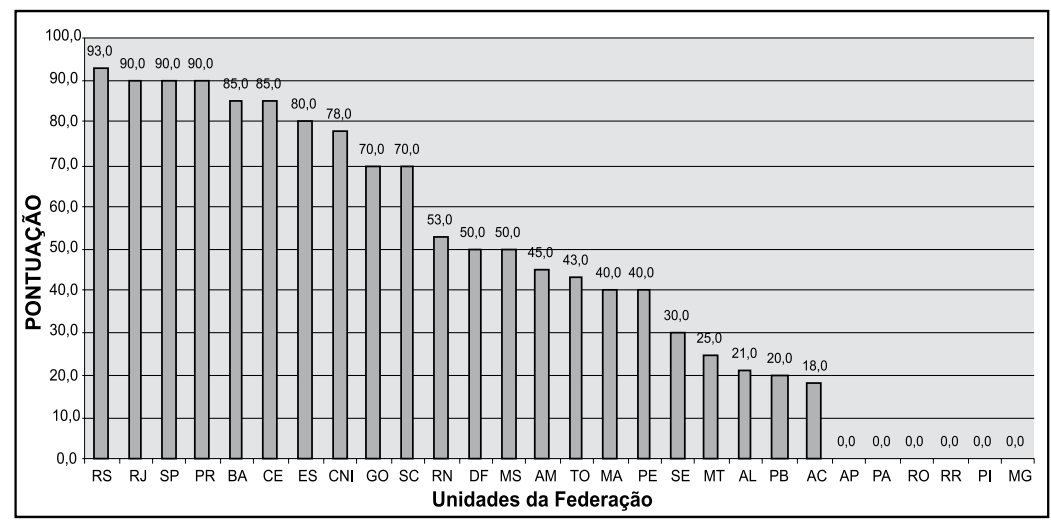

Gráfico 5 - Comunicação e informação

\subsection{Informações sobre Economia e Tecnologia}

Nesta dimensão, a pontuação dos itens foi elevada (Tabela 6), contudo, deve-se observar a baixa frequência de alguns quesitos relevantes, tais como "link para acompanhamento direto do PAC" $(3,6 \%)$, "informações sobre o funcionamento de agência reguladoras" $(3,6 \%)$ e outros programas importantes implantados pelo poder público, tanto em nível federal como estadual, embora já estar razoavelmente presente nos portais a veiculação de notícias sobre o andamento de tais programas e sobre o funcionamento desses novos órgãos governamentais. Pela análise das frequências dos itens presentes nos portais das federações, podemos observar que, 


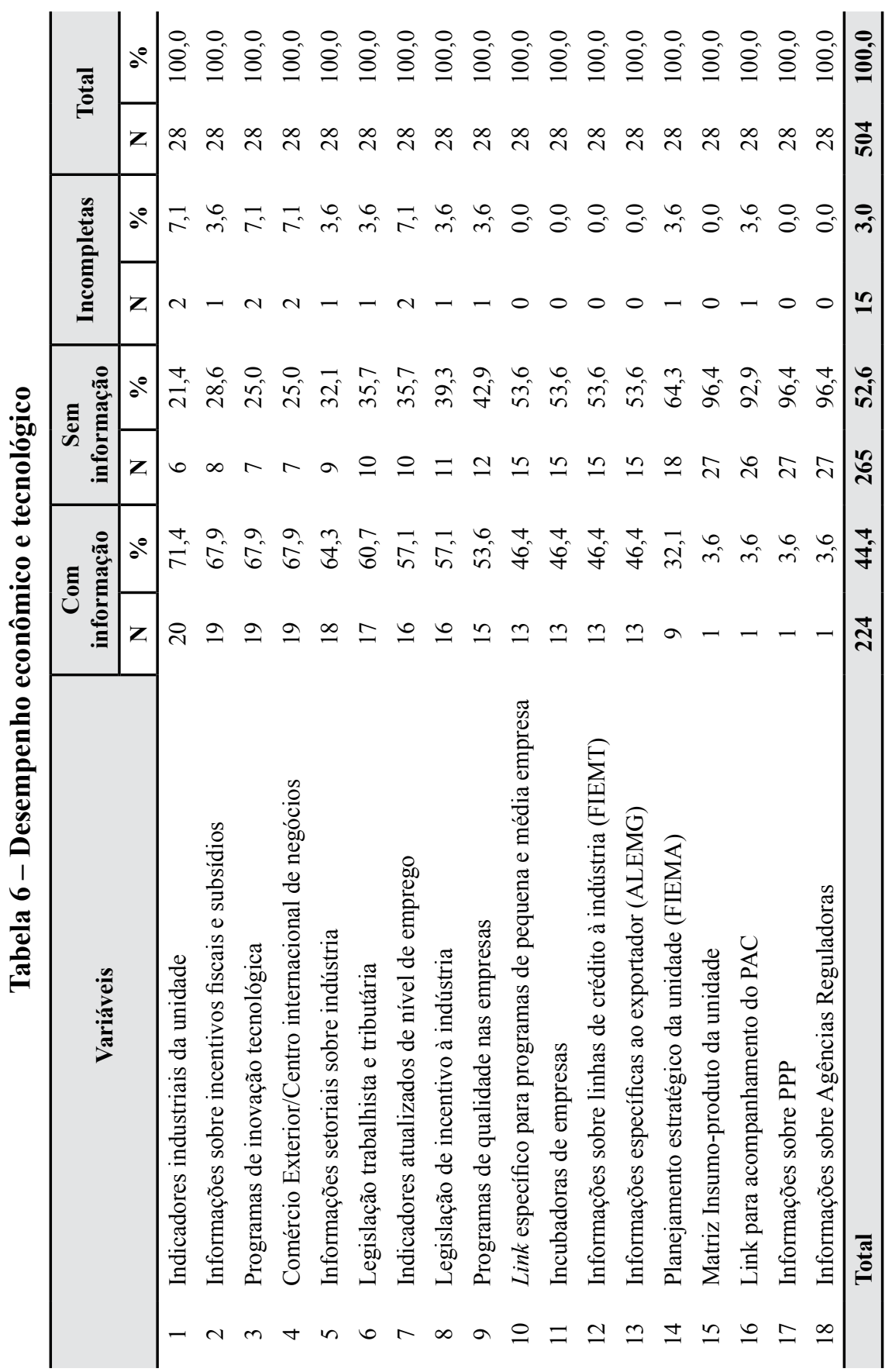




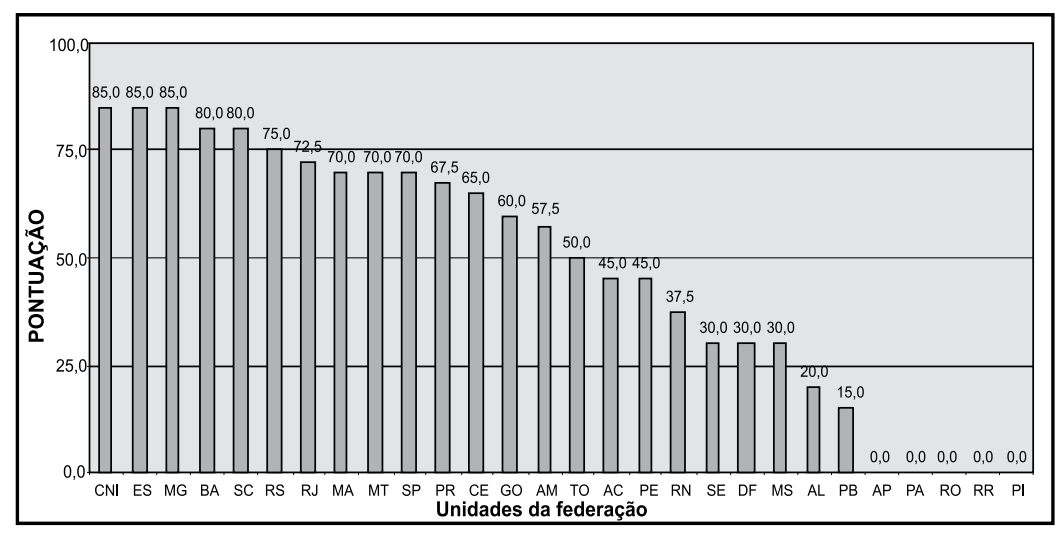

Gráfico 6 - Economia e tecnologia

embora esteja razoavelmente difundido o hábito de disponibilizar informações rotineiras sobre o desempenho industrial, ainda não é comum o uso dos websites de tais entidades para monitorar o andamento de programas governamentais específicos, relacionados com o desenvolvimento econômico e tencológico, por exemplo: as parcerias público-privadas, o funcionamento de agências reguladoras em unidades subnacionais de governo, e o Programa de Aceleração do Crescimento.

\subsection{Atividades políticas e cívicas}

Para os fins da presente análise, esta é a dimensão mais relevante e nela inserimos as ações e programas de "responsabilidade social" ", pois essas ações também visam à promoção da cidadania e à integração dos empresários industriais nas comunidades mais amplas da quais fazem parte. A Tabela 7 mostra as 22 atividades políticas identificadas nos portais examinados.

A expectativa inicial de encontrar atividades de natureza análoga às observadas no portal da FIEP não foi concretizada (Gráfico 7). Excluindo-se a divulgação de programas de responsa- 


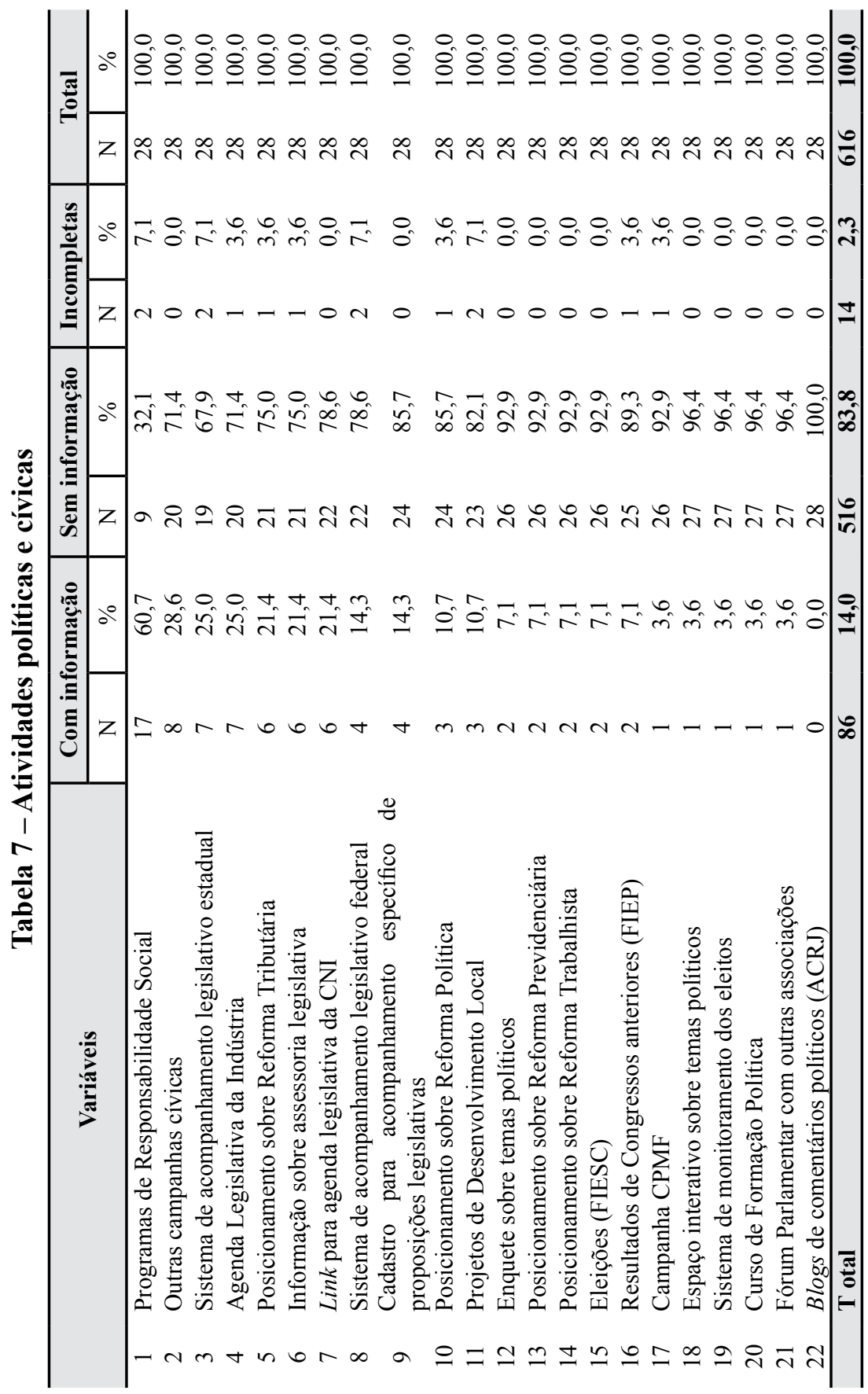


bilidade social $(60,7 \%)$, já amplamente difundidos na maior parte das entidades, as demais atividades políticas podem ser consideradas ações esporádicas nos websites das federações das indústrias.

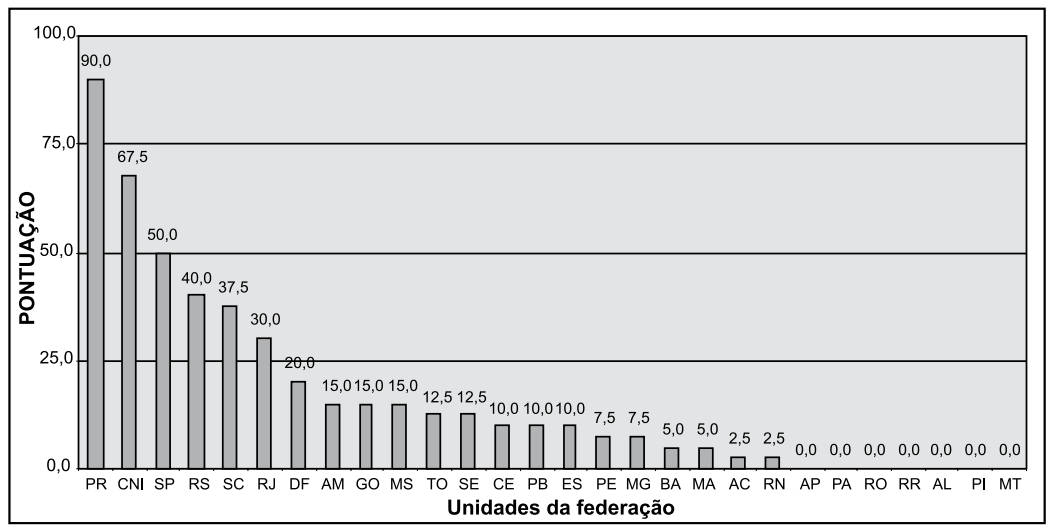

\section{Gráfico 7 - Informações sobre atividades políticas e cívicas}

\subsection{Integração em rede com outros órgãos}

Por fim, na Tabela 8 , relacionamos as entidades e associações encontradas nas "conexões em rede" estabelecidas pelos websites ou portais das federações de indústrias. Devemos esclarecer que as informações contidas no Gráfico 8 não correspondem ao conjunto dos links existentes nos portais das entidades examinadas para outras associações. Somente computamos aqueles vínculos que se encontram a uma distância máxima de dois cliques das páginas iniciais dos portais examinados, o que, a nosso ver, indicaria a efetiva intenção de estabelecer conexões com outras websites e entidades, e não uma inclusão meramente protocolar dos links nas home pages das federações. 


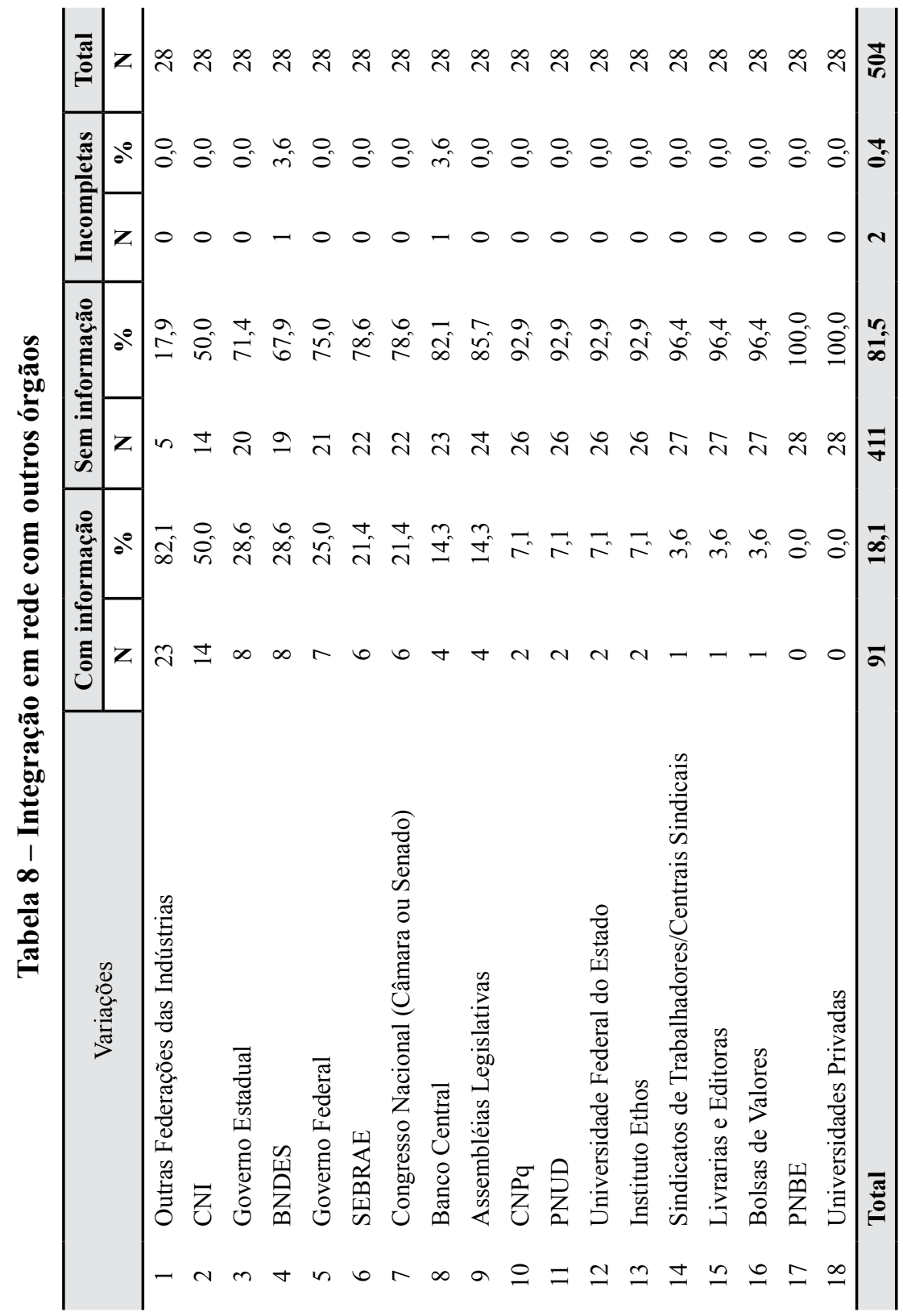




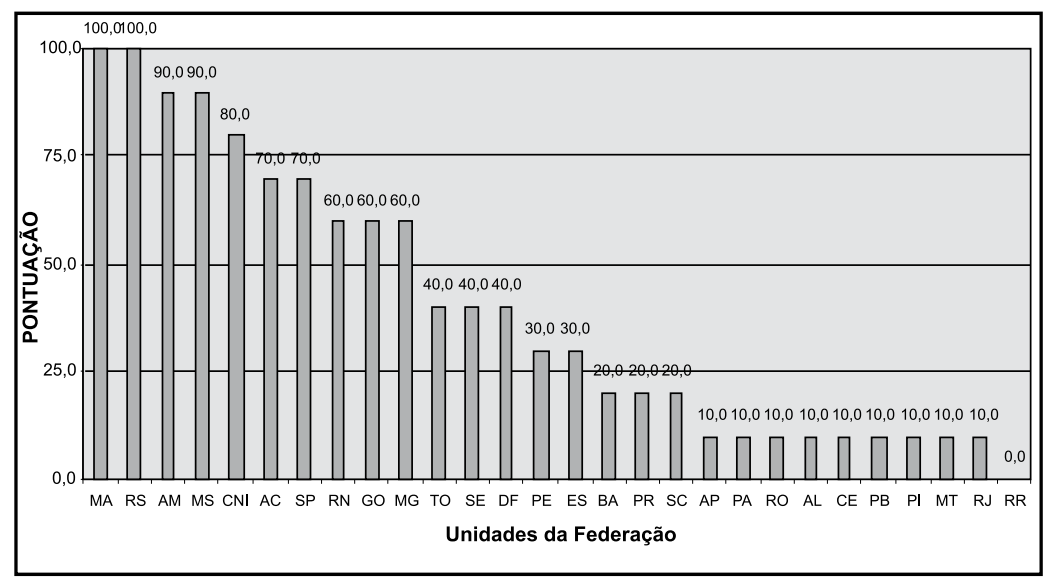

Gráfico 8 - Conexões em rede com outras associações relevantes

Com efeito, com a difusão da chamada Web 2.0, os portais dos diferentes atores políticos podem se constituir numa importante plataforma de construção de redes sociais e de coordenação mais ampla de atividades político-associativas, possibilitando assim a resolução de múltiplos problemas de ação coletiva, conforme evidenciado pela recente campanha eleitoral de Barack Obama (Gomes, 2005). Pelo Gráfico 8 podemos perceber que os portais das federações industriais analisadas já estão sendo utilizados como um importante instrumento de conexão com outros atores. Entretanto, a maior parte dos portais limita-se a inserir os links para outros websites, sem tentativas de construção de redes sociais propriamente ditas, ou seja, de formas "horizontais" e menos verticalizadas de ação associativa com outras entidades. Diga-se de passagem que, muitas vezes, o "inflacionamento" de links nas páginas iniciais dos portais serve para ocultar a deficiência de outros recursos de comunicação e participação políticas nas páginas iniciais das federações. De qualquer maneira, a existência dessas ligações já indica uma tentativa embrionária de estabelecer conexões com outros atores e não apenas usar o hyperlink como uma espécie de "outdoor virtual" ou instrumento "top down" de comunicação como o público. 


\section{Conclusões}

Podemos agora fazer uma análise global do comportamento das variáveis coletadas e uma análise do caso da Rede de Participação Política do Empresariado, iniciativa organizada pela FIEP.

Quanto ao "grau de informatização" dos portais das federações de indústrias, consolidando as informações apresentadas acima e agrupando os dados por região, por dimensão e por "índice global de informatização (ou de transparência)", temos os resultados da Tabela 9 .

Tabela 9 - Grau de informatização/transparência das associações industriais brasileiras - por dimensão e região

\begin{tabular}{lccccccccc}
\hline & Nav & Inst & Serv & Edu & Com & Eco & Pol & Rede & Total \\
\hline CNI/Federal & 65,0 & 40,0 & 60,0 & 65,0 & 78,0 & 85,0 & 67,5 & 40,0 & 67,6 \\
Norte & 13,3 & 23,1 & 30,1 & 18,6 & 15,1 & 21,8 & 4,3 & 16,4 & 24,5 \\
Nordeste & 46,1 & 46,7 & 54,1 & 37,9 & 41,6 & 40,3 & 5,8 & 17,2 & 35,3 \\
Centro-Oeste & 45,0 & 55,8 & 76,3 & 45,0 & 48,8 & 47,5 & 12,5 & 25,0 & 46,4 \\
Sudeste & 48,8 & 44,7 & 70,0 & 75,0 & 65,0 & 78,1 & 24,4 & 21,3 & 54,5 \\
Sul & 56,7 & 48,7 & 90,0 & 86,0 & 84,3 & 74,2 & 55,8 & 25,0 & 64,5 \\
\hline Média (item) & $\mathbf{4 5 , 8}$ & $\mathbf{4 3 , 2}$ & $\mathbf{6 3 , 4}$ & $\mathbf{5 4 , 6}$ & $\mathbf{5 5 , 5}$ & $\mathbf{5 7 , 8}$ & $\mathbf{2 8 , 4}$ & $\mathbf{2 4 , 2}$ & $\mathbf{4 8 , 8}$ \\
\hline
\end{tabular}

Fonte: Planilha anexa.

No tocante ao grau de uso da internet pelas diferentes regiões e unidades da federação, a Tabela 9 confirma, em linhas gerais, as expectativas iniciais de pesquisa de encontrarmos um maior grau de utilização da web em entidades de porte nacional (CNI) e nas Regiões Sul (64,5\%) e Sudeste $(54,5 \%)$. Também é confirmada a expectativa de encontrarmos um baixo índice de presença da web nas atividades de natureza política e cívica em comparação com outras dimensões. Atividades relacionadas a "Serviços" $(63,4)$ e "Economia e Tecnologia" $(57,8)$ são as que mais se destacam. 
Quanto ao desempenho global dos portais por entidade industrial em relação a uma pontuação máxima hipotética obtida a partir de um "portal ótimo" contendo todos os itens pesquisados, temos o resultado mostrado no Gráfico 9.

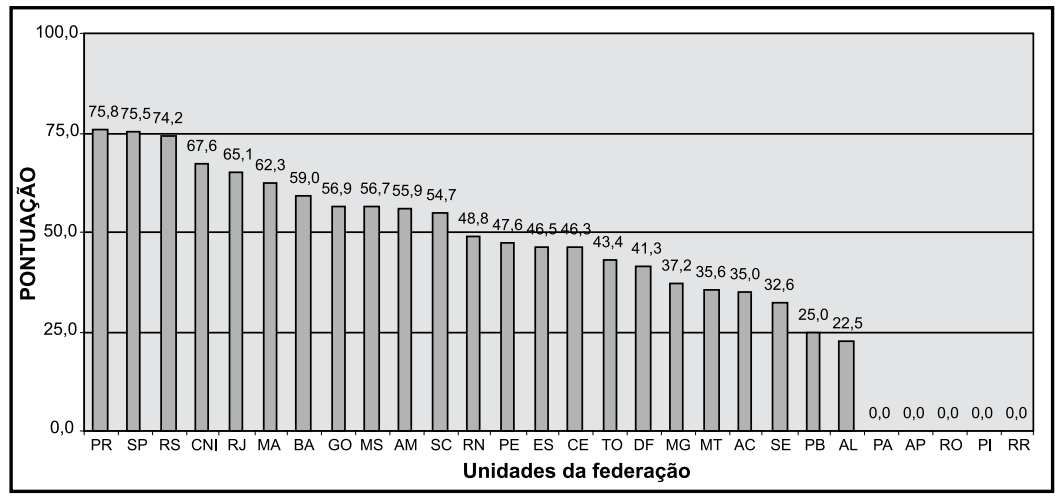

\section{Gráfico 9 - Desempenho global dos websites}

Destacam-se das demais, por possuírem um alto grau de transparência em seus portais durante o período em que foi efetuada pesquisa, a FIEP e a FIESP. Seguem-nas a FIERGS e a FIERJ com bom nível de informatização, mas seus websites não apresentam a mesma variedade de recursos das duas instituições líderes. Do total das 28 entidades examinadas, apenas 10 obtiveram níveis satisfatórios de informatização, 12 estiveram abaixo da média e 5 estiveram fora do ar durante o período de pesquisa. Portanto, de acordo com os critérios que utilizamos para avaliar os websites das federações de indústrias brasileiras, há muito trabalho a ser feito por essas entidades para aumentarem seu grau de comunicação e interação com a opinião pública.

Entretanto, mais relevante do que estabelecer um ranking, importa, para os nossos fins, empreender uma análise em profundidade das principais atividades políticas presentes nos websites a fim de avaliar como as federações estão utilizando este recurso para divulgar 
atividades cívicas e, por conseguinte, potencializar a inserção dos empresários na comunidade de que fazem parte.

Analisando os dados da Tabela 7, podemos encerrar nossa reflexão chamando a atenção para alguns fenômenos observados, destacando o caso da Rede de Participação Política do Empresariado, da FIEP, e apontando algumas singularidades dessa experiência visà-vis outras de natureza análoga desenvolvidas por outras federações de indústrias. Longe de querermos esgotar todas as possibilidades do tema, trata-se aqui apenas de reter alguns dados a serem retomados e desenvolvidos posteriormente através de estudos de caso com maior profundidade.

Das 22 atividades políticas que detectamos nos portais ou que levantamos a partir da análise da literatura, os itens de maior frequência são divulgação de ações e programas de responsabilidade social e campanhas cívicas diversas. ${ }^{8}$ Em seguida, com um grau bastante inferior, estão aquelas ações relacionadas ao acompanhamento de processos políticos que ocorrem em instituições representativas tradicionais, tais como sistema de acompanhamento legislativo $(25,0 \%)$, agenda legislativa da indústria $(25,0 \%),{ }^{9} \mathrm{e}$ posicionamento sobre questões em trâmite nos órgãos legislativos que afetem mais de perto os interesses corporativos do empresariado, tal como a reforma tributária $(21,4 \%)$. Por fim, num terceiro bloco de variáveis, podemos mencionar aquelas atividades políticas e cívicas de natureza menos "ortodoxa" (ou seja, voltadas para a promoção de ações de responsabilidade social ou de acompanhamento de decisões nos órgãos legislativos tradicionais) e orientadas para a promoção de formas mais participativas de democracia política. A esse respeito, são pouquíssimas as entidades empresariais que usam os respectivos portais para a divulgação e o estímulo de "projetos de desenvolvimento local" (10,7\%), como "espaço interativo de discussão de temas políticos", para "cursos de formação política", para divulgar o posicionamento do empresariado sobre temas mais 
gerais que formam a agenda pública (tais como reforma política e previdenciária), e outras experiências veiculadoras de uma concepção mais "participativa" da política e da cidadania, menos orientada à atuação em instâncias tradicionais de deliberação política (tais como os órgãos parlamentares).

Compreenderemos melhor a natureza dessas novas formas de ação política através da web se analisarmos com maior vagar os casos daquelas federações que utilizam com mais intensidade seus websites/portais para divulgar e promover atividades de cunho político, tais como a FIEP, a FIESP e a CNI.

\section{a) Atividades político-cívicas no portal da FIEP: o caso da Rede de Participação Política do Empresariado}

O portal da FIEP foi o que apresentou maior pontuação entre todos os examinados. Isso se deve ao fato de ele apresentar uma maior integração e uma distribuição bem equilibrada entre as várias dimensões da ação social do empresariado industrial passíveis de serem potencializadas a partir desses portais. Devemos reiterar, no entanto, que a FIEP se singulariza em relação às demais federações pelo elevado grau de presença de atividades políticas em seu portal. Assim, logo na página inicial há amplo destaque para um link para a Rede Empresarial (http://www.fiepr.org.br/redeempresarial/), evidenciando que as atividades políticas são uma dimensão de destaque na entidade. Há também acesso rápido para uma infinidade de atividades políticas. A singularidade do sítio da FIEP é que não há apenas uma atividade de acompanhamento legislativo e de ações orientadas para a indústria especificamente, mas também para a sociedade de uma maneira mais ampla e uma maior preocupação com a transparência e publicização dessas ações.

No sítio da FIEP constam várias e diversificadas atividades políticas e cívicas que utilizam a internet como um dos principais, se 
não o principal, meio de difusão. Dentre essas atividades, podemos listar como as mais importantes:

a) Rede de Participação Política do Empresariado (http:// www.redeempresarial. org.br/) - é a principal atividade política promovida pela instituição e que articula e centraliza todas as demais. Segundo palavras do presidente da FIEP, “(...) é um movimento apartidário criado para promover a articulação da sociedade por meio de ações sintonizadas com outras iniciativas do setor empresarial no âmbito nacional. Um de seus principais propósitos é estimular o empresariado e toda a sociedade a participarem continuamente da política". Ao longo de seus dois anos de existência, a Rede promoveu diversas ações práticas de desenvolvimento, alcançando mais de 5.000 cidadãos conectados em 24 Estados brasileiros, recrutou 5.300 participantes em cerca de 80 debates virtuais, realizou cursos capacitando cerca de 400 novos agentes no Paraná, desencadeou 26 projetos locais (comunitários), além de ter patrocinado um projeto político de desenvolvimento das cidades do Paraná em 10 regiões do Estado e realizado um curso permanente, totalmente on-line de formação política e cidadã, intitulado "Democracia, Redes Sociais e Sustentabilidade". ${ }^{10}$

b) Programa "Nós podemos Paraná" - estimula atividades comunitárias de desenvolvimento visando à persecução dos "objetivos do milênio", com destaque para a redução das desigualdades sociais através de iniciativas de desenvolvimento autossustentado (http://www. nospodemosparana.org.br/).

c) Exerça sua cidadania/reforma política - link para sítios destinados a discutir a reforma política (http://www. 
reformapolitica.org.br/) e estimular a participação do internauta em debates sobre o assunto.

d) Movimento das Cidades pela Educação Básica-programa de monitoramento e fiscalização da execução de programas de educação básica, especialmente em nível local (http:// www.cidadespelaeducacao.org.br/).

e) Sistema de Monitoramento e Avaliação dos Eleitos (SMAE) - é um processo contínuo de acompanhamento e apreciação do comportamento dos representantes executivos e legislativos nos níveis federal e estadual feito pela Rede de Participação Política do Empresariado em parceria com pesquisadores da Universidade Federal do Paraná (http://www.redeempresarial.org.br/monitora/).

f) Curso de formação política - programa de formação política que visa difundir o curso de formação política.

g) Projeto de política de desenvolvimento das cidades - promove iniciativas de desenvolvimento local e de empreendedorismo, mobilizando os cidadãos por meio de redes cívicas (http://www.redeempresarial.org.br/ Notes2218content23883.shtml). ${ }^{11}$

h) Banco de idéias - trata-se de um "Espaço destinado aos participantes da Rede de Participação Política do Empresariado para que apresentem temas para discussão ou ações de articulação. Os comentários ficam registrados e são intermediados pelo próprio autor. Os interessados em sugerir temas devem encaminhar mensagem para o e-mail rede.empresarial@fiepr.org.br. Os critérios para publicação são pautados nas "orientações" que constam na página inicial do sítio da Rede”.

i) Assessoria de Assuntos Legislativos - o serviço de monitoramento das atividades legislativas da Assembléia 
do Estado "consiste na identificação das proposições de interesse da indústria, divulgando-as e formulando alternativas mais convergentes com a agenda do setor. Nos moldes do trabalho desenvolvido pela COAL (Unidade de Assuntos Legislativos), órgão integrante da Confederação Nacional das Indústrias (CNI), um novo departamento, de caráter multidisciplinar, foi estruturado com o nome de Assessoria de Assuntos Legislativos da FIEP, responsável pela manutenção deste sistema. O trabalho consiste em identificar as principais proposições legislativas que afetam a competitividade das empresas, registrando o posicionamento do setor industrial em relação a cada uma delas. A divulgação deste trabalho é feita de duas maneiros: 1) pela Agenda Legislativa da Indústria do Paraná, uma publicação anual do roteiro dos principais temas de interesse do setor que tramitam na Assembléia durante o ano Legislativo; e 2) pela manutenção de um sítio (www.fiep.legisdata.cni.org.br) contendo a tramitação dos projetos de lei relevantes para o fomento industrial." A assessoria legislativa da FIEP publica dados biográficos sobre os deputados paranaenses, notícias produzidas por agência de notícias própria sobre eventos ocorridos no Legislativo estadual e no federal, e boletins informativos sobre as principais leis de interesse da indústria aprovadas ao longo das sessões legislativas. Também há um sistema de acompanhamento de tramitação de proposições, a ser acessado, mediante senha e cadastro, via intranet.

j) Conselho Paranaense de Cidadania Empresarial: responsável pelo desenvolvimento de vários programas de responsabilidade social e estímulo à cidadania (http:// www.fiepr.org.br/fiepr/cpce/).

k) Outros programas: o portal da FIEP mantém surveys on-line para avaliar a mentalidade política do cidadão- 
internauta (Teste na Rede), e disponibiliza os votos dados pela bancada paranaense na votação da CPMF (Programa Veja os Votos da Bancada), dentre outras atividades políticas e cívicas.

Em suma: a principal característica do portal da Federação das Indústrias do Paraná (FIEP) é utilizar de maneira intensiva a internet para promover atividades que visam não apenas a atuação do empresariado nas instituições tradicionais da democracia representativa e parlamentar, mas, também, integrar-se com a comunidade através da promoção da participação política.

\section{b) O sítio da FIESP}

No caso da principal entidade estadual de representação de interesses dos industriais brasileiros, podemos observar que não há destaque para nenhuma atividade política na página inicial da Federação das Indústrias do Estado de São Paulo(FIESP), excetuando notícias sobre algumas campanhas cívicas de que participa.

O sítio é particularmente frugal em relação a declarações do empresariado sobre os temas políticos mais candentes do momento. As principais atividades políticas encontradas estão localizadas no link intitulado FIESP/Brasília, onde estão como que "ocultas" as atividades políticas da Fiesp, todas elas sintomaticamente mais voltadas para ações em Brasília do que para o seu Estado ou comunidade de origem. Há uma série de sublinks, dos quais podemos destacar os seguintes:

a) Sistema de Acompanhamento Legislativo (SALF) - "o industrial pode pesquisar, com atualização diária, as proposições legislativas que tramitam no Congresso Nacional, seja pelo número, autor, sindicatos filiados à FIESP, ramo industrial, cadeia produtiva e tema." $\mathrm{O}$ 
Sistema dispõe de informações personalizadas, tais como ementa explicativa, proposições de ação prioritária e espaço para opinar e sugerir. O SALF é um importante instrumento de fluxo de trabalho e posicionamento dos diversos Conselhos, Departamentos e Comitês da FIESP.

b) Entenda os Três Poderes: breve explicação sobre o funcionamento do Legislativo, do Executivo e do Judiciário e sobre o fluxo das decisões políticas em Brasília.

c) Síntese política - síntese das principais resoluções de interesse da indústria publicadas no Diário Oficial da União (http://www.fiesp.com.br/brasilia/sintese_diario. aspx).

d) Atividades legislativas - seleção semanal das novas proposições de interesse da indústria e acompanhamento de atividade legislativa da semana em pauta no Plenário e nas Comissões.

e) Você em Brasília - informações sobre Brasília e agência de lobby de interesse do empresariado.

Em suma: a entidade busca privilegiar a proximidade com supostas instâncias centrais de poder e decisão, mais do que as atividades destinadas a promover a participação política, a fiscalização popular sobre o processo decisório, a implementação de programas governamentais, ou de atividades que visam à integração dos empresários com suas comunidades e localidades de origem.

\section{c) O sítio da CNI}

No sítio da CNI há vários links para assuntos políticos, mas não há um domínio exclusivo para atividades políticas, nem atividades interativas com o cidadão-internauta. Algumas das mais importantes atividades nele encontradas são as seguintes: 
a) Assuntos jurídicos - sistema de acompanhamento para Ação Direta de Inconstitucionalidade (ADI), que tem sido um dos principais instrumentos de intervenção dos grupos lesados por medidas aprovadas no Congresso, dada a “judicialização” da política no Brasil (Vianna, 2002).

b) Assuntos legislativos - nesse link estão as principais ações políticas desenvolvidas na internet pela entidade e, basicamente, consiste num sítio de monitoramento das proposições de interesse da indústria que tramitam no Congresso Nacional. O internauta tem acesso à Agenda Legislativa da Indústria, contendo os projetos de interesse que tramitam no Legislativo e o posicionamento da indústria sobre eles. As agendas de 2006 e 2007 podem ser baixadas gratuitamente.

c) Legisdata - sistema de acompanhamento de tramitação legislativa, sempre de temas de interesse da indústria, que só é acessado mediante senha.

d) Reforma tributária e previdenciária - há vários arquivos e publicações com posicionamento da indústria sobre estes assuntos, mas não muitas coisas sobre reforma política.

e) Há também agenda e projetos de política pública.

Em suma: as arenas de atuação política privilegiadas pelo CNI são as tradicionais, tais como acompanhamento de processo legislativo, o posicionamento da indústria em relação a políticas públicas tradicionais e sugestão de agenda. Há pouca tentativa de "publicizar" a intervenção política mais ampla da indústria ou de propiciar elementos de interatividade com o cidadão-internauta, evidenciando que predomina nesses segmentos das elites empresariais uma visão tradicional da política como aquelas atividades que se passam na esfera do Estado, nos poderes governamentais, em detrimento das atividades mais voltadas para a articulação de setores 
da sociedade civil visando à promoção mais autônoma da cidadania no tocante ao poder público.

\section{d) Conclusões gerais}

Há bastante heterogeneidade nos websites das federações de indústrias, tanto de conteúdo como de formato de apresentação. Assim, podemos observar a existência de portais que equilibram de maneira razoável as várias dimensões da ação social do empresariado, até federações de regiões menos desenvolvidas que não possuem portais na Web, ou que apresentam frequentes problemas técnicos de acesso.

Os portais das federações industriais ainda são pouco utilizados para desenvolver atividades políticas, vis-à-vis outras atividades voltadas para o empresariado e para a opinião pública. Entretanto, alguns portais já disponibilizam em seus domínios uma ampla gama de recursos destinados a potencializar a ação política de tais atores, porém essas ações ainda revelem uma concepção mais tradicional da atividade política, estando focadas em programas de responsabilidade social e na atuação das instituições tradicionais da democracia representativa, especialmente em órgãos parlamentares.

Dentre todos os websites examinados, entretanto, podemos observar algumas experiências inovadoras de uso dos recursos da internet para a promoção e para o estímulo de atividades políticas. Dentre essas experiências, destaca-se, promovida pela FIEP, a Rede de Participação Política do Empresariado, que articula uma série de outras iniciativas inovadoras visando à ampliação da participação política do empresariado e, especialmente, uma maior integração deste segmento social com sua comunidade de origem.

O caráter "inovador" dessas experiências reside no fato de elas transcenderem os limites da política e da democracia 
parlamentar tradicional, estimulando a participação política da população e a explicitação dos pontos de vista do empresariado em relação aos temas que fazem parte da agenda pública, tornando mais transparente a ação desse grupo social e fortalecendo, assim, o controle e monitoramento da sociedade civil sobre Estado.

\section{Notas}

1 Sendo que incluímos também em nossa pesquisa a CNI (Confederação Nacional das Indústrias), devido ao razoável número de atividades políticas no sítio da instituição e também pelo motivo de ser ela quem, em grande parte, centraliza e coordena as ações políticas das entidades empresariais localizadas nas esferas subnacionais de governo.

2 Nossa intenção inicial era verificar se se reproduziam em outras unidades da Federação e em outras entidades empresariais projetos de participação e integração política do empresariado com a comunidade de natureza análoga aos atualmente desenvolvidos na FIEP, especialmente o Sistema de Avaliação e Monitoramento dos Eleitos. Para maiores informações sobre o sistema de monitoramento citado, cf. $<$ http://www. vigilantesdademocracia.com.br/>.

3 A tese segundo a qual a internet apenas reproduz "a política como usual", reiterando formas de ação política já estabelecidas no "mundo real" é defendida no trabalho já clássico de Margolis e Resnik (2000). Cf. especialmente o capítulo 3: "Parties and interest groups: organizing lobbying, and electioneering cyberspace" (p. 53-75), onde os autores defendem a tese de que as associações civis e grupos de pressão dominantes tendem a consolidar seu domínio no espaço virtual, não difundindo novas formas de atuação política nem possibilitando espaço à ação de novos segmentos sociais: "What has occurred is the normalization of cyberspace. Cyberspace has not become the locus of a new politics that spills out of the computer screen and revitalizes citizenship and democracy. If anything, ordinary politics and commercial activity, in all their complexity and vitality, have invaded and captured cyberspace. Virtual reality has grown to resemble the real world" (p. 2). 
Para uma visão alternativa, cf. Pippa Norris (2001, capítulo 9: “Civic Society", p. 171-192).

4 Durante o período de pesquisa não conseguimos acessar os websites das federações das indústrias do Amapá, Pará, Rondônia e Roraima, que estiveram fora do ar durante todo o período pesquisado. Por sua vez, o da Federação das Indústrias do Estado do Piauí, embora estivesse no ar por alguns períodos de nossa pesquisa, apresentou vários problemas de funcionamento e navegação, motivo pelo qual optamos por excluí-la de nosso estudo.

5 Sublinhe-se que os percentuais observados nos portais das federações de indústrias são superiores aos obtidos em pesquisa que efetuamos no início de 2007 nos portais legislativos brasileiros, quando verificamos que $62,1 \%$ apresentavam baixo grau de navegabilidade, não disponibilizando ao cidadão-internauta alguns recursos básicos com vistas a estimular sua navegação na internet (Braga, 2007, p. 49).

6 Quando tais mecanismos de buscas restringiam-se apenas às notícias postadas, pontuamos a variável como "insatisfatória" ou "incompleta".

7 Programas de Responsabilidade Social são aqueles que as empresas implementam para criar uma cultura de gestão que busca impactar positivamente, através de iniciativas visando ao desenvolvimento local, todos os públicos afetados pelas ações das empresas. Para um maior detalhamento, cf. as informações contidas no sítio do Instituto Ethos: $<$ http://www.ethos.org.br>.

8 "Campanhas cívicas diversas" abrange reivindicações de obras específicas de interesse coletivo em determinadas regiões (por exemplo, construção do Porto de Cabedelo, na Paraíba), campanhas de apoio a projetos de saúde pública (caso da dengue no Rio de Janeiro), fiscalização de determinadas obras governamentais etc.

9 Um mecanismo de intervenção política bastante difundido nos sítios das federações das indústrias são as agendas legislativas, explicitando o posicionamento das federações sobre os temas que estão em tramitação nas Assembléias Estaduais. Desenvolvidas a partir da experiência 
bem-sucedida da CNI, o posicionamento das federações no tocante a esses documentos é, via de regra, apresentado de forma bastante clara e explícita.

10 Segundo depoimento do atual presidente da FIEP, Rodrigo Rocha Loures, a criação da Rede, em abril de 2006, está fortemente relacionada à repercussão do "escândalo do mensalão", e de seus impactos e desdobramentos sobre o funcionamento do sistema político brasileiro. Ainda de acordo com o presidente da FIEP, a crise de credibilidade do sistema político brasileiro na segunda parte do primeiro mandato do presidente Lula levou segmentos expressivos do empresariado paranaense à percepção de que seriam necessárias novas formas de participação política, mais participativas e próximas à comunidade, distintas das formas de participação em que os empresários costumam se engajar, tais como financiamento de campanhas eleitorais e atuação como grupo de pressão em ações específicas de interesse do empresariado paranaense.

11 Segundo o portal da FIEP: "A idéia básica do projeto é a seguinte: a Rede de Participação Política no âmbito local (inicialmente nas 10 cidades-pólo do Paraná e, depois, nos municípios que, polarizados por tais cidades, compõem a microrregião) deverá ser também uma rede que promove o desenvolvimento a partir dos seus componentes políticos (sintetizados num pacto pela democracia local, compreendendo: a reforma da política em âmbito local e a construção de novos sistemas de governança capazes de promover sinergias entre a atuação do governo, das empresas e das organizações da sociedade civil para a consecução de uma agenda endógena de desenvolvimento democrático).”

Entrepeneurs, politics and the Web: mapping political activities in the web portals of the industry federation

Abstract: This paper's main objective is to present the results of a research about the "informatization level" of web portals of the industry federation of 27 Brazilian subnational units, especially a map of political activities developed by the members who make use of such portals. The main objective brings about two specific 
objectives: a) to present a proposal for measurement of the informatization level and Internet usage by the local chapters of the industry federation and other similar initiatives by the business class, aimed at evaluating how these entities use the Web to promote their activities and interact with the general public; b) elaborate and apply theoretical and methodological tools for the analysis of such information, especially to evaluate the effectiveness of the Internet as a tool for both organization of political action and public engagement by the business class.

Keywords: Internet and Politics; corporate political action; Federation of Industries.

\section{Referências bibliográficas}

BOSCHI, R.; DINIZ, E.; SANTOS, F. Elites políticas e econômicas no Brasil contemporâneo: a desconstrução da ordem corporativa e o papel do Legislativo no cenário pós-reformas. São Paulo: Fundação Konrad Adenauer, 2000.

BRAGA, S. O papel das TICs na institucionalização das democracias: um estudo sobre a informatização dos órgãos legislativos na América do Sul com destaque para o Brasil. Brasília: Plenarium, Cedi, 2007. Disponível em: <http://www2.camara.gov.br/internet/eve/ realizados/portal_seminario2007/material.html>. Acesso em: 25 abr. 2007.

DINIZ, E.; BOSCHI, R. Empresários, interesses e mercado. Belo Horizonte: UFMG, 2004.

GOMES, W. Democracia digital: que democracia? Paper apresentado na II Compolítica, realizada em Belo Horizonte de 5 a 7 de dezembro de 2007.

MANCUSO, W. P. O lobby da indústria no Congresso Nacional: empresariado e política no Brasil contemporâneo. Dados, Revista de Ciências Sociais, Rio de Janeiro, v. 47, n. 3, p. 505-547, 2004. 
MANCUSO, W. P. O empresariado como ator político no Brasil: balanço da literatura e agenda de pesquisa. Revista de Sociologia e Política, Curitiba, n. 28, p. 131-146, jun. 2007.

MARGOLIS, M.; RESNICK, D. Politics as usual: the cyberspace “revolution”. Thousand Oaks, CA: Sage Publications, 2000.

OLIVEIRA, A. J. S. N. O papel da coalizão empresarial brasileira e as negociações da ALCA. 2003. Tese (Doutorado em Ciência Política) - Universidade de São Paulo, 2003.

POWER, T.; DOCTOR, M. The resilience of corporatism: continuity and change in Brazilian corporatist structures. Oxford: Centro de Estudos Brasileiros, 2002.

SCHNEIDER, B. R. Business politics and the State in twentieth-century Latin America. New York: Cambridge University, 2004.

VIANNA, L. W. (Org.). A democracia e os três poderes no Brasil. Belo Horizonte: UFMG; Rio de Janeiro: Iuperj, Faperj, 2002. 


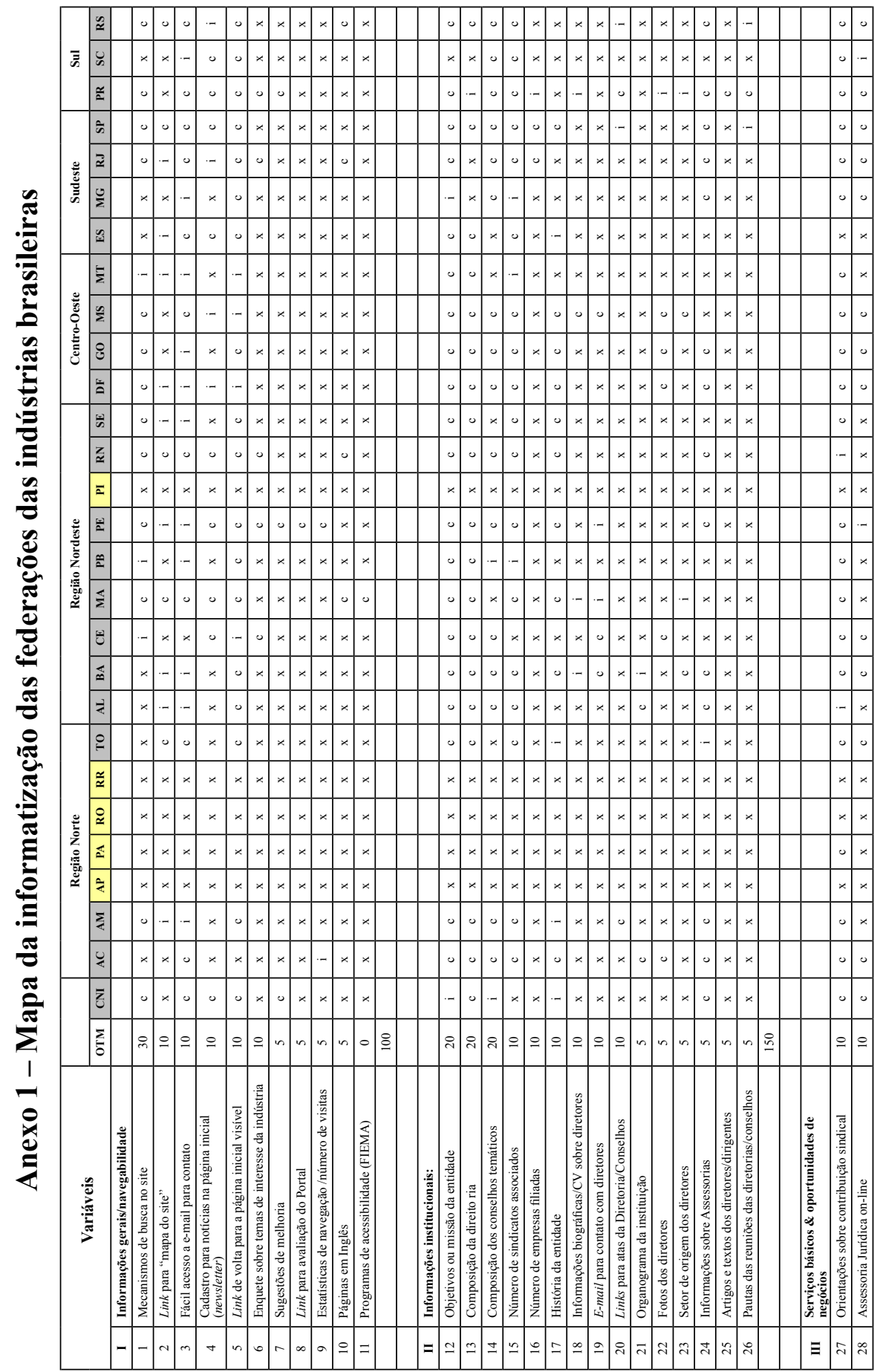




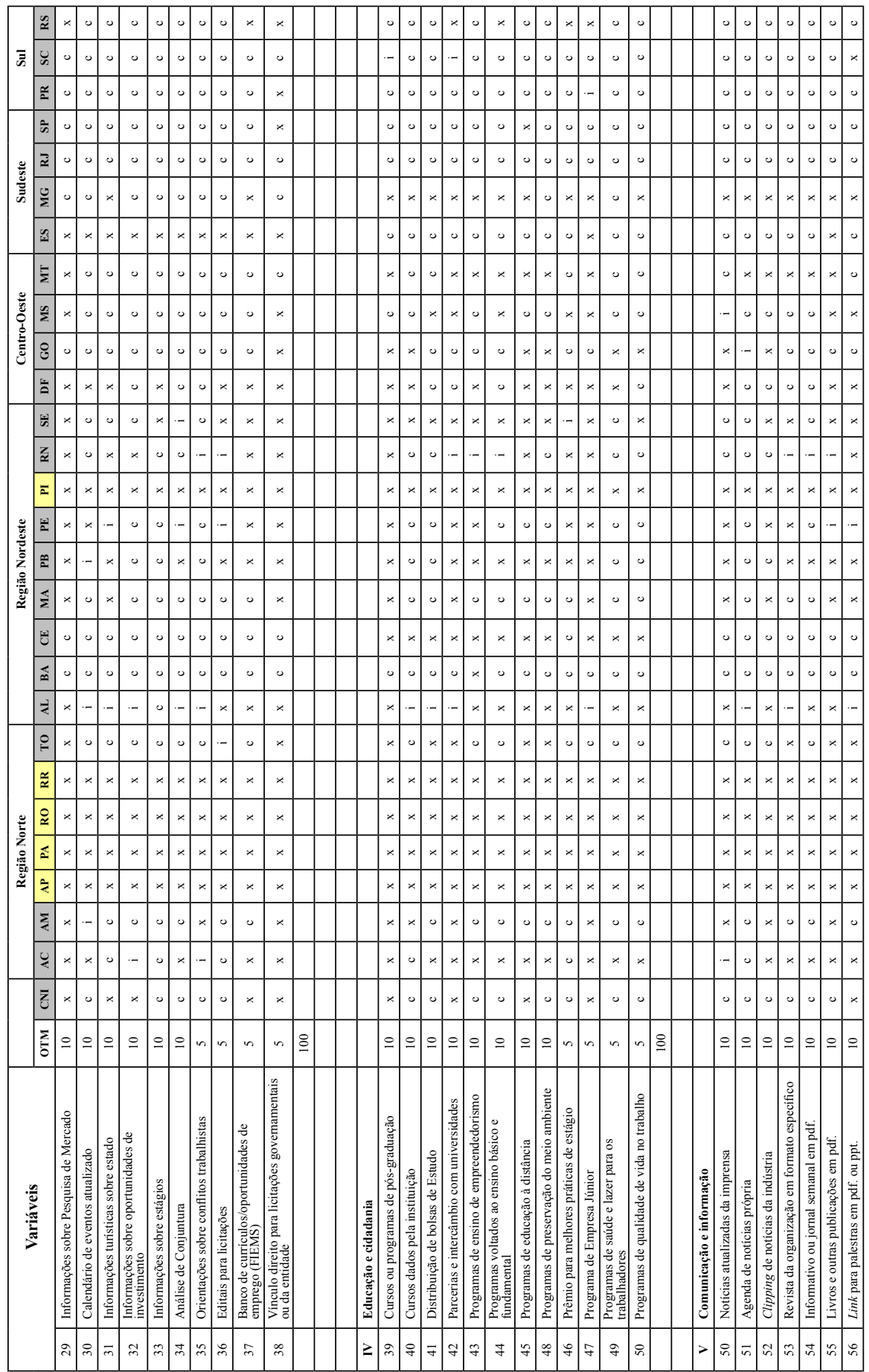




\begin{tabular}{|c|c|c|c|c|c|c|c|c|c|c|c|c|c|c|c|c|c|c|c|c|c|c|c|c|c|c|c|c|c|c|c|c|}
\hline \multirow{3}{*}{$\bar{\vdots}$} & $\approx 0$ & $x$ & 0 & -1 & 0 & 0 & & & 0 & 0 & 0.0 & 0 & 0 & 0 & - & & 。 & 0 & $\star 1$ & 0. & 0 & 0 & $\star$ & $\times *$ & & & 0 & 0 & & 0 & & $x$ \\
\hline & $\begin{array}{c}u \\
.\end{array}$ & * & ن & $\approx$ & $*$ & $*$ & & & 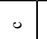 & 0 & 0.0 & 0 & 。 & 0 & 0 & & 0 & 0 & $\star 1$ & 0 & & o & $\approx$ & $*$ & & & $*$ & $*$ & 0 & 0 & & . \\
\hline & $\frac{\pi}{2}$ & 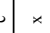 & & 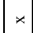 & 0 & 。 & & & & 0 & 0.0 & 0 & 。 & . & 0 & 0 & 0 & 0 & $\times$ & * & & 0 & $\star 1$ & $\star *$ & & & o & 0 & & 。 & & 0 \\
\hline \multirow{4}{*}{$\bar{\Sigma} \overline{\bar{\Delta}}$} & 0 & $*$ & 0 & 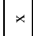 & 0 & 0 & & & & 0 & 0.0 & 0 & 。 & 0 & ०. & 0 & 0 & 0 & $\star 1$ & $\times \mid \propto$ & & 0 & $*$ & $* *$ & & & 0 & 0 & 0 & 0 & & $\star x$ \\
\hline & $\vec{z}$ & * & 0 & 0 & $\star x$ & . & & & . & $-\square$ & 0. & - & 。 & 。 & ०. & & 0 & 0 & $\star$ & 0 & & 0 & $*$ & 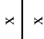 & & & * & * & 0 & 0 & & * \\
\hline & 气ू & * & $\star$ & $*$ & $*$ & $\times$ & & & 0 & \begin{tabular}{|l|l|l} 
& \\
\end{tabular} & .0 & . & 0 & 0 & . & & 。 & - & $\times$ & 0. & 。 & 。 &. & $\times *$ & & & . & $*$ & $*$ & 0 & & * \\
\hline & 迴 & 0 & 0 & 0 & $*$ & $*$ & & & 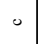 & 0 & 0.0 & 0 & 。 & 0 & . & . & 0 & - & 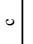 & 0 & & 。 & $*$ & $* *$ & & & 0 & $*$ & $\star 1$ & 0 & & $x$ \\
\hline \multirow{4}{*}{ : } & $\Xi$ & 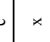 & $\star$ & $*$ & $*$ & $\star$ & & & & 0 & 0.0 & 0 & 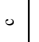 & & . & & 0 & - & $\times$ & 0 & & $*$ & $\star$ & $\times \mid \times$ & & & $*$ & $*$ & $*$ & $\star$ & & $x$ \\
\hline & $\frac{n}{2}$ & * & $\star$ & 0 & $*$ & $\star$ & & & $*$ & $\approx$ & 0. & $\star$ & . & $*$ & $*$ & & 0 & $\star$ & $*$ & $0 *$ & 。 & * & $\star$ & $* \mid *$ & & & * & * & 0 & $\times$ & & * \\
\hline & 8 & * & o & 0 & 0 & 0 & & & 0 & 0. & 0.0 & - & 。 & o & 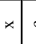 & . & 0 & - & $\times$ & $0 \times$ & * & $*$ & $\star$ & $\times \mid \times$ & & & 0 & $*$ & & $*$ & & * \\
\hline & 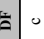 & * & $\star$ & $\approx$ & 0 & $*$ & & & 0 & \begin{tabular}{|l|l|}
0 &
\end{tabular} & .0 & 0 & * & * & $*$ & * & * & $*$ & $\star$ & $* *$ & * & $*$ & $\star$ & 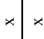 & & & 0 & $*$ & $*$ & 0 & & x \\
\hline \multirow{9}{*}{ 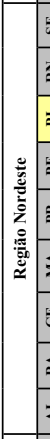 } & : & * & * & $*$ & $*$ & $\star$ & & & 0 & 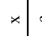 & 0.0 & 0 & 。 & $*$ & * & 0 & $\star$ & $*$ & $\times$ & $* *$ & * & $*$ & $*$ & \begin{tabular}{l|l}
$*$ & $*$
\end{tabular} & & & * & $*$ & 0 & 0 & & $\times$ \\
\hline & $\underline{z}$ & * & * & 0 & $*$ & $\star$ & & & - & $*$. & $-x=$ & $\times$ & $\star$ & $*$ & $\circ$. & $\circ$ & 0 & 0 & $\star$ & $* *$ & & 0 & $*$ & $\star * x$ & & & $*$ & $*$ & $*$ & - & & * \\
\hline & 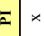 & * & * & $*$ & $*$ & $*$ & & & $*$ & $*$ & $\approx=$ & $*$ & * & * & $*$ & $*$ & $*$ & $*$ & $\star$ & 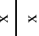 & * & $*$ & $*$ & $* *$ & & & $*$ & $*$ & $*$ & $*$ & & 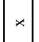 \\
\hline & & * & 0 & $*$ & $*$ & $\star$ & & & $*$ & $\approx$ & 01 & $*$ & 。 & $*$ & ०. & 0 & 0 & 0 & $\star$ & $0 \times$ & 0 & 0 & $*$ & $* \mid *$ & & & $*$ & $*$ & $*$ & 0 & & × \\
\hline & $\approx$ & * & * & $*$ & $*$ & $\star$ & & & $*$ & $*$ & $\times=$ & $\star$ & $\star$ & * & . & . & 0 & $*$ & $\times$ & $\star *$ & * & * & $\star$ & $* \mid *$ & & & $*$ & $*$ & $*$ & - & & $\star$ \\
\hline & 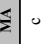 & * & o & 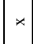 & $*$ & $\star$ & & & 0 & 0. & 0.0 & 0 & 。 & 0 & $\circ$. & & 0 & - & $*$ & $\times 0$ & * & . & $*$ & $* *$ & & & $*$ & $*$ & & 0 & & * \\
\hline & (8) & * & o & 0 & $*$ & $\star$ & & & 。 & 0 & 0.0 & 0 & 。 & $*$ & * & $* 1$ & . & . & $*$ & 0 & 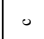 & 0 & $*$ & $* \mid *$ & & & $*$ & - & $*$ & . & & x \\
\hline & $\bar{\varpi}$ & * & 0 & 0 & $*$ & $\star$ & & & 0 & 0 & 0.0 & 0 & 。 & 0 & ०. & 0 & 0 & - & $\times$ & 0 & 0 & 0 & $*$ & $* \mid *$ & & & $*$ & $*$ & $*$ & 0 & & * \\
\hline & 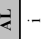 & * & - & $\approx$ & $*$ & $\times$ & & & $\star 1$ & $\approx$. & $--=$ & $\times$ & - & * &.- & - & - & -- & $\times$ & $0 \times$ & * & $*$ & $*$ & $* \mid *$ & & & $*$ & $*$ & & $*$ & & * \\
\hline \multirow[b]{2}{*}{ 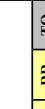 } & $=$ & * & * & - & $*$ & $*$ & & & o & 0 & 0.0 & 0 & 。 & $*$ & $\star$ & 0 & 0 &. & $\star$ & $\times$ & * & $*$ & $\approx$ & $* \mid *$ & & & - & $*$ & $*$ & . & & $\approx$ \\
\hline & $\approx$ & * & * & * & $*$ & $\star$ & & & $*$ & $\approx$ & $* x$ & $\times$ & $\star$ & * & $\star$ & $\star$ & $\times$ & $\star$ & $\times$ & $\times$ & * & $*$ & $*$ & $* \mid *$ & & & $*$ & $*$ & & $\times$ & & $x$ \\
\hline \multirow{7}{*}{$\approx$} & ๕ & * & * & $\approx$ & $\star x$ & $\star$ & & & * & 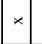 & $*=$ & $\star$ & $*$ & $*$ & $*$ & $\star$ & * & $*$ & $\star$ & 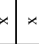 & * & * & $*$ & $* *$ & & & * & $*$ & $*$ & $\star$ & & * \\
\hline & \begin{tabular}{l|l}
\multirow{2}{*}{$*$} \\
\end{tabular} & * & * & $*$ & $*$ & $*$ & & & * & $*$ & $\times 1$ & $*$ & $\star$ & * & $*$ & $\star$ & $*$ & $*$ & $\times$ & $\times x$ & * & $*$ & $\star$ & \begin{tabular}{l|l}
$*$ & $*$
\end{tabular} & & & $*$ & $*$ & & $\star$ & & * \\
\hline & $\frac{1}{z}$ & * & * & $\approx$ & $*$ & $\times$ & & & $\times$ & $\approx$ & $\times 1$ & $\times$ & $\star$ & $*$ & $*$ & $\times$ & * & $*$ & $\times$ & $\times$ & * & $*$ & $\times$ & 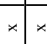 & & & * & $*$ & $\times$ & $\times$ & & * \\
\hline & छ & * & * & $*$ & $*$ & $\star$ & & & $\lambda$ & 0 & 0.0 & 0 & 。 & 。 & - & . & 0 & - & $\times$ & $0 \times$ & 2 & $*$ & - & $* *$ & & & $*$ & - & & 0 & & x \\
\hline & 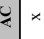 & * & - & $\approx$ & $*$ & $\star$ & & & 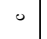 & 0 & 0.0 &. & 。 & & $\star$. & & - & - & $*$ & $\star \approx$ & & $*$ & $*$ & $* \approx$ & & & $*$ & $*$ & & - & & $x$ \\
\hline & $\bar{z}$ & * & 。 & -- & 0 & $*$ & & & o & 0 & 0.0 & - & 。 & 0 & - & & 0 & - & $\times$ & $\times 0$ & & 0 & $*$ & 0.0 & & & 0 & 0 & & - & & × \\
\hline & $\bar{E}$ & in & in & in & in & $i 8$ & & & $\therefore$ & ণ & $\therefore=$ & $\odot=$ & $\subseteq$ & $\subseteq$ & 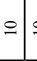 & $=$ & $\therefore$ & 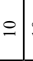 & $\circ$ & $=\circ$ & & $\subseteq$ & $\therefore$ & $\therefore=$ & & & 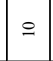 & $\varrho$ & & 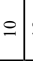 & & 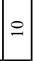 \\
\hline \multirow[t]{2}{*}{ 旅 } & 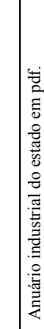 & 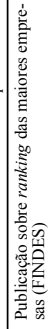 & 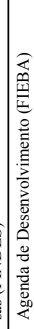 & 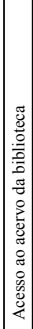 & 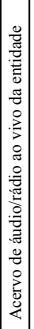 & & & 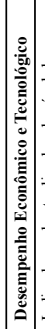 & 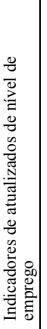 & 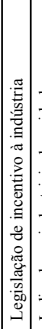 & 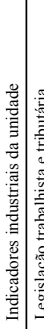 & 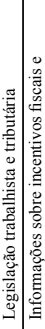 & 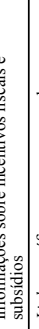 & 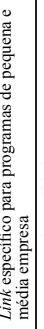 & 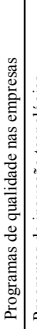 & 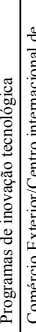 & 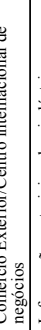 & 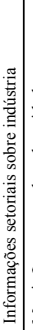 & 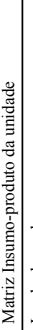 & & 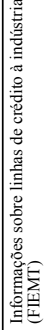 & 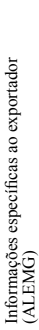 & 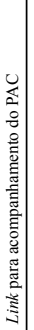 & 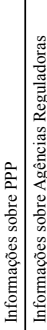 & & & 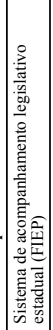 & 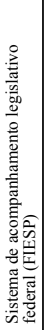 & 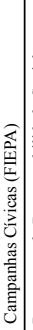 & 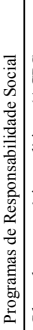 & 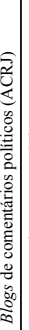 & \\
\hline & & $\stackrel{\infty}{n}$ & in & 8 & & $\widehat{\sigma}$ & & $=$ & 8 & If & $\because 8$ & $: 5$ & 6 & $\infty$ & 8 & & 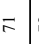 & $\approx$ & $\approx$ & \pm & & $F$ & $\infty$ & $\therefore \varnothing$ & & $\Xi$ & $\vec{\infty}$ & $\approx$ & & 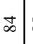 & $\approx$ & $\infty$ \\
\hline
\end{tabular}




\begin{tabular}{|c|c|c|c|c|c|c|c|c|c|c|c|c|c|c|c|c|c|c|c|c|c|c|c|c|c|c|c|c|c|c|c|c|c|c|}
\hline & $\approx$ & $x$ & -- & $\approx$ & * & 0 & $*$ & $\star *$ & * & 0 & 0 & $x$ & $*$ & $\times$ & $\star$ & & & & 10 & 0 & 0 & 0 & 0 & $\times$ & 0 & 1 & $x$ & 0 & $\approx$ & $\star x$ & & & & * \\
\hline$\overline{\bar{n}}$ & 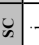 & 。 & 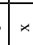 & & . & * & 0 & $\times$ & * & * & 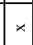 & $\approx$ & 0 & 0 & * & & & $x$ & 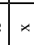 & $x$ & 0 & $\approx$ & * & $*$ & 0 & 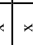 & * & * & $*$ & $*$ & & $*$ & & $\approx$ \\
\hline & $\cong$ & م & 10 & 0 & D. & 。 & $\star$ & 0 & 0 & 0 & 0 & 0 & 0 & $*$ & $x$ & & & $x$ & $\approx$ & $*$ & . & $*$ & $x$ & $\approx$ & 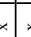 & $x$ & 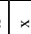 & * & $\approx$ & $*$ & & 0 & & $\approx$ \\
\hline & है & 。 & 0 & $x$ & $x$ & * & 0 & $\times$ & 0 & 0 & 0 & $\approx$ & $\star x$ & $\star 1$ & * & & & & 0 & 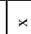 & . & 0 & 0 & $\star$ & 0. & $x$ & : $x$ & 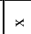 & $x$ & $*$ & & $\approx$ & & $x$ \\
\hline g & $\bar{\Sigma}$ & 。 & $\approx$ & $\approx$ & $\approx$ & * & $*$ & $\star *$ & 0 & 。 & 0 & $\approx$ & $*$ & $\star$ & * & & & $x$ & $\approx$ & $\approx$ & 0 & $*$ & $*$ & $\star$ & $\star$ & 6 & * & * & $\approx$ & $*$ & & $\approx$ & $\star$ & $\approx$ \\
\hline $\mathscr{m}$ & & $x$ & 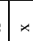 & $*$ & . & * & $*$ & 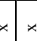 & $\approx$ & $*$ & $\star x$ & $\approx$ & $* 1$ & $*$ & * & & & $x$ & 0 & . & 。 & $*$ & $*$ & $*$ & . & 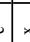 & $*$ & * & $*$ & $*$ & & $*$ & & * \\
\hline & & $x$ & $x$ & $x$ & $x$ & $x$ & $x$ & $1 \times$ & $\approx$ & & $\star$ & 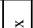 & $\neq 1$ & $\approx 1$ & & & & & 0 & ax & 0 & * & 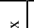 & $*$ & $\star$ & & 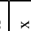 & $*$ & I & 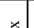 & & $x$ & & $\times$ \\
\hline & $\Xi$ & $x$ & $\approx$ & $\approx$ & $*$ & * & $\star 1$ & $x$ & * & $*$ & $x$ & $\approx$ & $*$ & $\times 1$ & & & & & 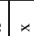 & 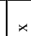 & . & $*$ & $*$ & $\times$ & $*$ & 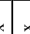 & 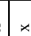 & . & $\times$ & $*$ & $\approx 1$ & $\approx$ & & $\times$ \\
\hline & $\frac{n}{2}$ & 0 & $\approx$ & $*$ & × & $*$ & $\star 1$ & 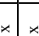 & $*$ & $*$ & $*$ & $\approx$ & $*$ & $\star 1$ & 。 & & & 0 & 0 & 0 & 0 & $\star x$ & 0 & & $\times$ & & $x$ & O & $x$ & $|x|$ & & & & $x$ \\
\hline & 8 & $x$ & $x$ & $*$ & . & $\approx$ & $*$ & $x=$ & * & * & 0 & $\approx$ & $*$ & $\star$ & 。 & & & $x$ & 60 & $x$ & . & 0 & 0 & $\approx$ & $*$ & 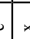 & 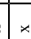 & * & $\approx$ & $*$ & & $\approx$ & & $\approx$ \\
\hline & $\stackrel{\Delta}{\Xi}$ & x & $\approx$ & $\approx$ & . & * & $*$ & $\times$ & * & 。 & $\approx$ & $\approx$ & $\approx$ & $\star 1$ & 。 & & & & 0 & 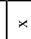 & . & $*$ & 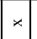 & $\star$ & $\star$ & & $x$ & . & $\approx$ & $*$ & & & $\star$ & * \\
\hline & : & $x$ & $\approx$ & $\approx$ & $\approx$ & - & $\star$ & 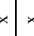 & * & $*$ & $*$ & $\approx$ & $\approx$ & $\times$ & * & & & & 0 & * & 0 & $*$ & 0 & $\star$ & $*$ & 4 & $*$ & * & $*$ & $*$ & & $*$ & & 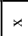 \\
\hline & $z$ & $x$ & $x$ & $x$ & $\star x$ & $\approx$ & $* 1$ & 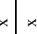 & $*$ & * & $x$ & $\approx$ & $\approx$ & $*$ & * & & & $x$ & 0 & $x$ & . & 0 & 0 & $\approx$ & $*$ & $x$ & 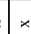 & * & 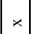 & $*$ & * & $\approx$ & & 0 \\
\hline & $\bar{\Xi}$ & * & $\approx$ & $*$ & $\approx$ & * & $\star$ & $\times$ & * & * & $*$ & $\approx$ & $\approx$ & $\times$ & * & & & $x$ & 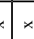 & 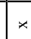 & . & $*$ & 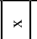 & $\star$ & $*$ & 6 & $x$ & * & * & $*$ & * & $\approx$ & & $\approx$ \\
\hline 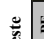 & & x & 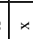 & $*$ & | & * & $\star 1$ & $\times$ & $*$ & $\star$ & $-\cdots$ & $\approx$ & $* 1$ & $\times$ & * & & & & 0 & . & O & $*$ & 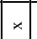 & $\star$ & $*$ & 6 & $x$ & * & 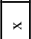 & $*$ & & $\approx$ & & $\approx$ \\
\hline & $\cong$ & * & 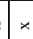 & $\approx$ & $\approx$ & * & $\star 1$ & $\times$ & $*$ & $\star$ & $*$ & $\approx$ & $* 1$ & $*$ & 。 & & & $x$ & $\Leftrightarrow \times$ & $*$ & . & $*$ & $\approx$ & $*$ & $*$ & $x$ & 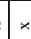 & $\approx$ & $*$ & $*$ & * & $*$ & $*$ & $\approx$ \\
\hline 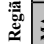 & 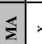 & x & 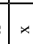 & $\approx$ & $\approx$ & $*$ & $*$ & 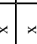 & * & * & 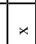 & $\approx$ & $\approx 1$ & $\star 1$ & * & & & & 0 & 0 & . & $*$ & . & $\star$ & 0. & 1 & 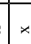 & 0 & 0 & 0 & & & & * \\
\hline & E & x & 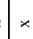 & $\approx$ & $\approx$ & * & $\star$ & $\times=$ & * & - & $*$ & $\approx$ & $\star 1$ & $*$ & * & & & & 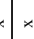 & $\times$ & 0 & $*$ & $\approx$ & $*$ & $*$ & $<x$ & $x$ & $\approx$ & $*$ & $*$ & & & $*$ & $\approx$ \\
\hline & $\grave{œ}$ & * & $*$ & $*$ & . & $*$ & $*$ & $\times$ & * & * & $*$ & $\approx$ & $*$ & $\star$ & $*$ & & & 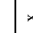 & $x$ & $\approx$ & . & $*$ & $\star *$ & 0 & 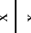 & 1 & $=$ & * & $*$ & $*$ & * & $*$ & $\star$ & $\approx$ \\
\hline & $z$ & $x$ & 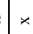 & 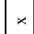 & * & * & $*$ & $x$ & * & * & $x$ & $\approx$ & $*$ & $\times$ & $*$ & & & $x$ & $x$ & 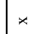 & . & $*$ & $\approx$ & $\star$ & $*$ & & : & $x$ & & $*$ & $\star$ & & & $\approx$ \\
\hline & \& & x & 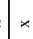 & $\approx$ & 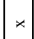 & $*$ & $*$ & $\times x$ & $*$ & $\approx$ & 0 & $\approx$ & $*$ & $* 1$ & * & & & & 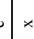 & 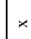 & 0 & $*$ & $*$ & $\star$ & . & 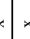 & $x$ & $x$ & & $*$ & $\star$ & & $*$ & $\approx$ \\
\hline & $\approx$ & $x$ & $\approx *$ & $\approx$ & 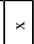 & $*$ & $\star$ & $\times$ & * & $*$ & 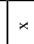 & $\approx$ & $*$ & $\times$ & * & & & $x$ & $x$ & $*$ & * & $*$ & $*$ & $\star$ & $*$ & & $x$ & 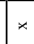 & $\approx$ & $\approx$ & * & & & * \\
\hline & ‡ & $x$ & $\approx$ & $\approx$ & . & $*$ & $*$ & $*$ & * & * & 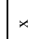 & $\approx$ & $*$ & $\star 1$ & * & & & & 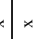 & $*$ & 0 & $*$ & $\approx$ & & $*$ & 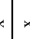 & $x$ & $x$ & & $*$ & & & & * \\
\hline & $\Xi$ & $\star$ & 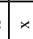 & $*$ & | & * & $\star 1$ & $\approx *$ & $*$ & * & 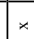 & $\approx$ & $\approx$ & $\times$ & $*$ & & & $x$ & 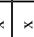 & $*$ & . & $*$ & $*$ & $\star$ & $*$ & 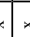 & $*$ & 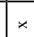 & $x$ & $*$ & * & & & $\approx$ \\
\hline$\cong$ & $\Leftrightarrow$ & $x$ & 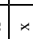 & $*$ & * & * & $\star$ & $* *$ & $*$ & x & $x$ & $\approx$ & $*$ & $\times$ & * & & & $x$ & 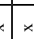 & $*$ & . & $\approx$ & * & * & $\times$ & $x$ & $x$ & * & & $*$ & * & & & * \\
\hline & $\equiv$ & $\star$ & 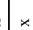 & $\approx$ & . & $\ldots$ & $\star 1$ & $\approx *$ & * & $*$ & $x$ & $\approx$ & $*$ & $*$ & 0 & & & 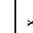 & 0 & 0 & o & $*$ & 0 & $\times$ & . & $x$ & $x$ & . & & $*$ & & & & . \\
\hline & Uِ & $x$ & $\approx$ & $*$ & 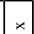 & $*$ & $* 1$ & $\times x$ & * & $*$ & $x$ & $*$ & $*$ & $\times$ & * & & & 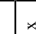 & 0 & $*$ & o & $*$ & $*$ & $\star$ & $\star=$ & 0 & 0 & 0 & & o & * & & $*$ & * \\
\hline & $\bar{z}$ & 。 & 0 & . & 0 & 0 & $*$ & $* x$ & 。 & 。 & . & $\approx$ & - & $\times$ & 。 & & & 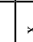 & 0 & 0 & . &. & $-\ldots$ & $\times$ & . & 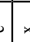 & $x$ & 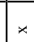 & & $*$ & * & & & * \\
\hline & $\Xi$ & 。 & 0 & $\circ$ & 0 & 0 & $\circ$ & 0 & 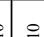 & $\circ$ & 0 & in & in & inl & ing & & & & 0 & 0 & . & 0 & 0 & 0 & 0 & 0 & 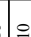 & 0 & 0 & $\circ$ & 。 & & & 0 \\
\hline 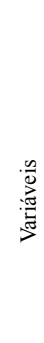 & है & 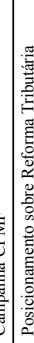 & 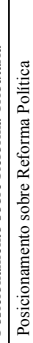 & 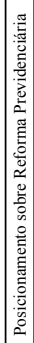 & 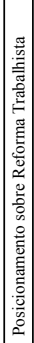 & 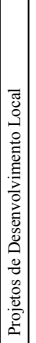 & 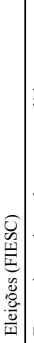 & 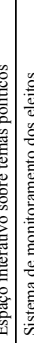 & 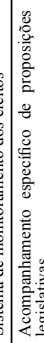 & 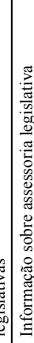 & 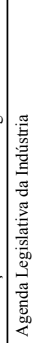 & 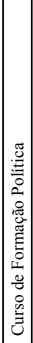 & 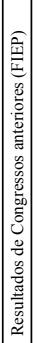 & 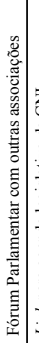 & & & & $\frac{\pi}{5}$ & 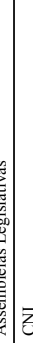 & & 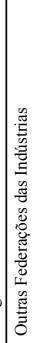 & 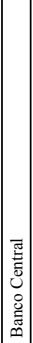 & 岱 & 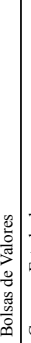 & 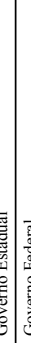 & 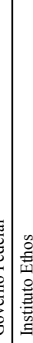 & 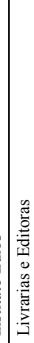 & 寝 & & 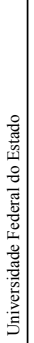 & & & 寝 & 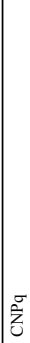 \\
\hline & & & & & $\bar{\sigma}$ & $\approx$ & & \pm & ঃ & 5 & $\approx$ & مू & 8 & $\Xi$ & & & & & \pm & $\stackrel{\varrho}{\circ}$ & $\cong$ & $\supseteqq$ & $\stackrel{\circ}{\circ}$ & 8 & 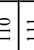 & $E=$ & $\cong$ & \pm & & 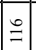 & & $\stackrel{\infty}{=}$ & 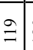 & \\
\hline
\end{tabular}

